\title{
Test Vehicle Forebody Wake Effects on CPAS Parachutes
}

\author{
Eric S. Ray ${ }^{1}$ \\ MRI Technologies (JETS), Houston, TX, 77058
}

\begin{abstract}
Parachute drag performance has been reconstructed for a large number of Capsule Parachute Assembly System (CPAS) flight tests. This allows for determining forebody wake effects indirectly through statistical means. When data are available in a "clean" wake, such as behind a slender test vehicle, the relative degradation in performance for other test vehicles can be computed as a Pressure Recovery Fraction (PRF). All four CPAS parachute types were evaluated: Forward Bay Cover Parachutes (FBCPs), Drogues, Pilots, and Mains. Many tests used the missile-shaped Parachute Compartment Drop Test Vehicle (PCDTV) to obtain data at high airspeeds. Other tests used the Orion "boilerplate" Parachute Test Vehicle (PTV) to evaluate parachute performance in a representative heatshield wake. Drag data from both vehicles are normalized to a "capsule" forebody equivalent for Orion simulations. A separate database of PCDTV-specific performance is maintained to accurately predict flight tests. Data are shared among analogous parachutes whenever possible to maximize statistical significance.
\end{abstract}

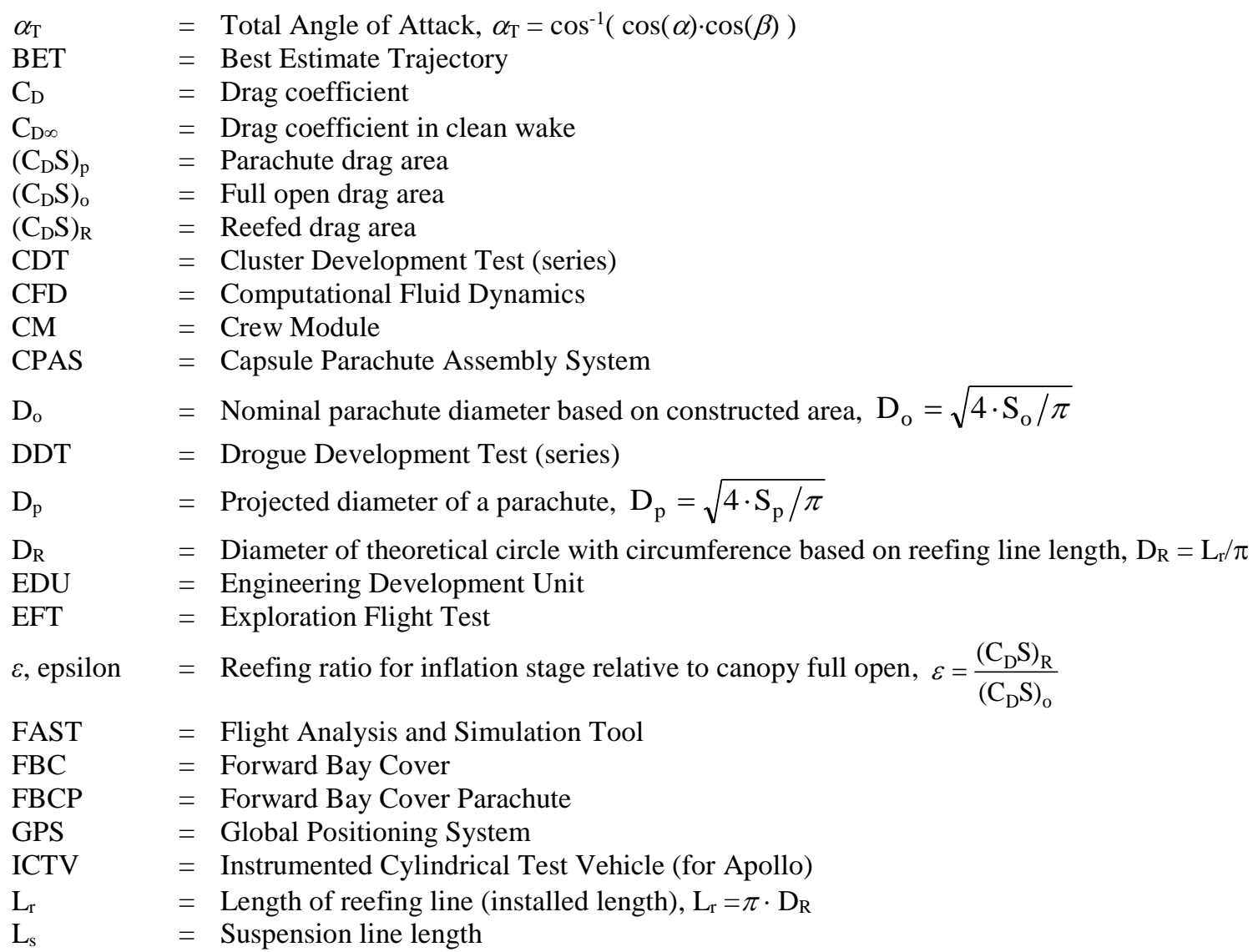

\footnotetext{
${ }^{1}$ Analysis Engineer, Aerosciences, Flight Dynamics and GN\&C, 2224 Bay Area Blvd, Houston, TX, AIAA Senior Member.
} 


$\begin{array}{ll}\text { LVAD } & =\text { Low Velocity Aerial Delivery } \\ \text { MDT } & =\text { Main Development Test (series) } \\ \text { MDTV } & =\text { Medium Drop Test Vehicle } \\ \text { MPCV } & =\text { Multi-Purpose Crew Vehicle (Orion) } \\ \mathrm{N}_{\mathrm{c}} & =\text { Number of parachutes in a cluster } \\ \mathrm{N}_{\mathrm{G}} & =\text { Number of gores in a parachute canopy } \\ \mathrm{PCDTV} & =\text { Parachute Compartment Drop Test Vehicle } \\ \mathrm{PRF} & =\text { Pressure Recovery Fraction, PRF }=\overline{\mathrm{q}} / \overline{\mathrm{q}}_{\infty}=\left(\mathrm{C}_{\mathrm{D}} \mathrm{S}\right)_{\mathrm{p}} /\left(\mathrm{C}_{\mathrm{D}} \mathrm{S}\right)_{\infty} \\ \mathrm{PTV} & =\text { Parachute Test Vehicle (Orion "boilerplate" or cone-shaped vehicle for Apollo) } \\ \overline{\mathrm{q}}, \mathrm{qbar} & =\text { Dynamic pressure, } \overline{\mathrm{q}}=\frac{1}{2} \cdot \rho \cdot \mathrm{V}_{\text {air }}{ }^{2} \\ \overline{\mathrm{q}}_{\infty} & =\text { Freestream dynamic pressure } \\ \mathrm{SDTV} & =\text { Small Drop Test Vehicle } \\ \mathrm{S}_{\mathrm{o}} & =\text { Parachute Canopy open reference area based on constructed shape } \\ \mathrm{S}_{\mathrm{p}} & =\text { Projected frontal canopy area } \\ \mathrm{S}_{\mathrm{R}} & =\text { Reefed geometric area, } \mathrm{S}_{\mathrm{R}}=\frac{\pi \cdot \mathrm{D}_{\mathrm{R}}{ }^{2}}{4}=\frac{\mathrm{L}_{\mathrm{r}}{ }^{2}}{4 \cdot \pi} \\ \mathrm{SPAN} & =\text { Synchronized Position Attitude \& Navigation } \\ \tau, \text { tau } & =\text { Geometric reefing-line ratio, } \tau=\frac{\mathrm{D}_{\mathrm{R}}}{\mathrm{D}_{\mathrm{o}}} \text { or } \tau=\frac{\mathrm{L}_{\mathrm{r}}}{\pi \cdot \mathrm{D}_{\mathrm{o}}} \\ \mathrm{V}_{\text {air }} & =\text { Total airspeed relative to air mass }\end{array}$

\section{Introduction}

$\mathrm{T}$ HE Capsule Parachute Assembly System (CPAS) program uses different parent aircraft and test vehicles to achieve diverse test objectives in preparation for human flight. Some tests must use a streamlined body to achieve a high deployment altitude and airspeed, while others require similitude to the Orion Multi-Purpose Crew Vehicle (MPCV). The forebody effects of these test articles must be taken into account when evaluating parachute performance.

The evolution of CPAS test vehicles and techniques is summarized on a timeline in Figure 1. ${ }^{1,2,3}$ Bars for each test technique show the period of technique development through testing. Generations (Gen) I and II used the slender Small Drop Test Vehicle (SDTV, 12.75 inch diameter) and Medium Drop Test Vehicle (MDTV, 24 inch diameter) for single-parachute tests. These "darts" had negligible wake effects. Cluster Development Tests (CDT) transitioned to weight tubs mounted on Low Velocity Aerial Delivery (LVAD) Type V platforms. These were essentially flat plates which generated considerable buffeting on Drogue parachutes, especially when deployed during load transfer while still in close proximity to the parent aircraft. The two flagship test articles were developed in preparation for Engineering Development Unit (EDU) testing. The missile-shaped Parachute Compartment Drop Test Vehicle (PCDTV) allowed for stable high-speed deployments with representative suspension hardware and could be extracted from either a C-130 or C-17. ${ }^{4}$ The Parachute Test Vehicle (PTV) provided an Orion "boilerplate" which was somewhat truncated in height in order to fit in a C-17. ${ }^{5}$ The latter two vehicles are currently in use for the qualification portion of the test program.

American Institute of Aeronautics and Astronautics 


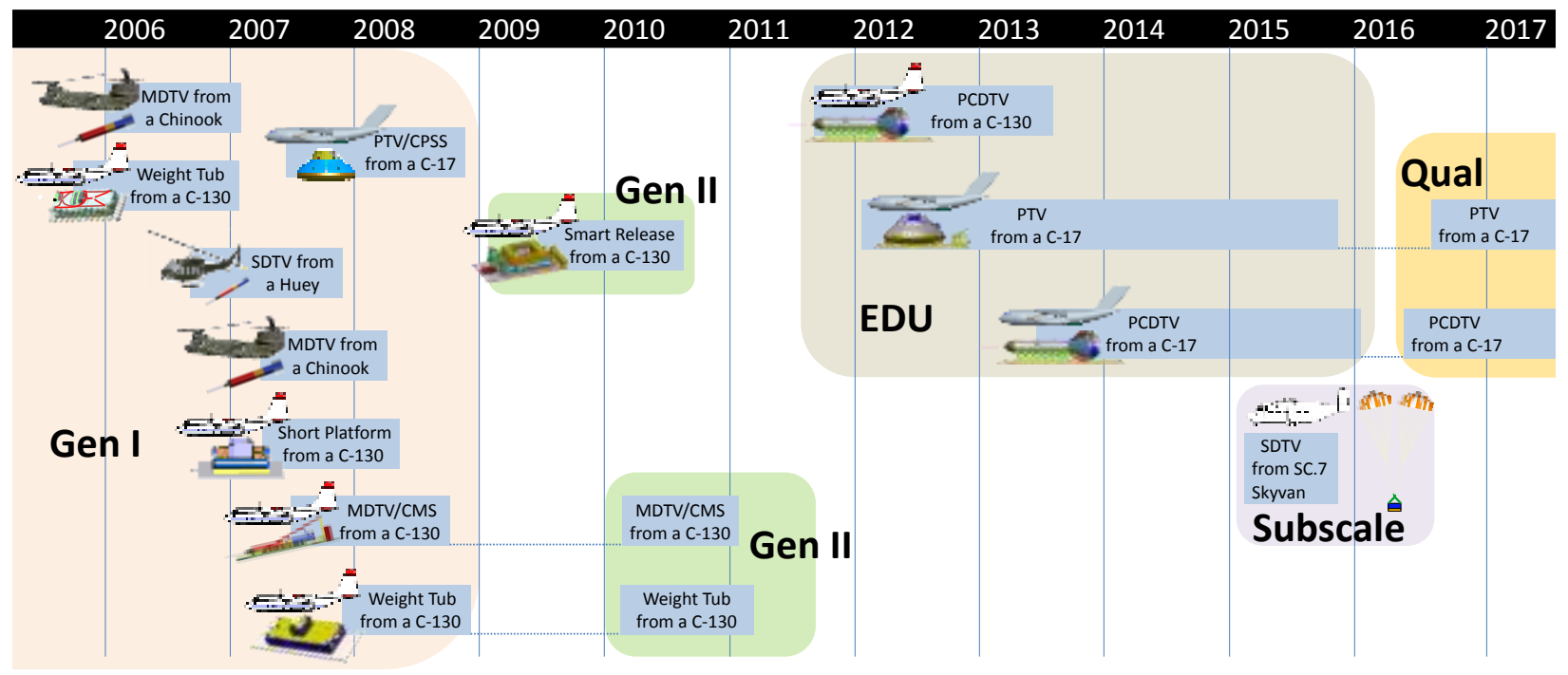

Figure 1. Evolution of CPAS test vehicles and techniques.

A summary of the physical dimensions of the parachutes that comprise CPAS are listed in Table 1. The Forward Bay Cover Parachute (FBCP), Drogue, and Pilot have similar conical ribbon designs which allows for sharing some flight data. The Main parachute has a quarter spherical ringsail design for safely landing the MPCV. At each reefing stage, Drogue and Main inlets are each restricted by the reefing lines to a theoretical reefed diameter $\left(D_{R}\right)$. The full open projected diameter $\left(D_{p}\right)$ for each assumes a reduction factor of 0.7 from the reference diameter, per Knacke. ${ }^{6}$ If necessary, the actual canopy size can be determined through photogrammetry. ${ }^{7,8}$ This assumption of the canopy size allows for calculating the range of trailing distance $\left(\mathrm{L}_{\mathrm{T}}\right)$ at both deployment (sum of riser length, $\mathrm{L}_{\mathrm{R}}$, and suspension line length, $\mathrm{L}_{\mathrm{s}}$ ) and at full open, where the distance is reduced by the canopy geometry. The trailing distances are expressed in terms of test vehicle forebody diameters $\left(\mathrm{D}_{\mathrm{B}}\right)$. The PCDTV has a maximum diameter of only 106 inches while the Orion heat shield diameter is 198 inches. As a rule of thumb, forebody effects are generally considered significant for trailing distances less than about six body diameters. Therefore, it is expected that Pilots will be the most affected by the Orion forebody wake and Mains will be the least affected.

Table 1. Summary of CPAS Parachute Physical Geometry

\begin{tabular}{|c|c|c|c|c|c|c|}
\hline \multirow{3}{*}{ Parachute } & \multirow{2}{*}{$\begin{array}{c}\text { Number } \\
\text { of } \\
\text { Gores, } \\
\mathbf{N}_{\mathbf{G}}\end{array}$} & \multirow{2}{*}{$\begin{array}{c}\text { Reference } \\
\text { Diameter, } \\
\text { Do }\end{array}$} & \multirow{2}{*}{$\begin{array}{l}\text { Reefed or } \\
\text { Projected } \\
\text { Diameter, } \\
\text { D }_{\mathrm{R}} \text { or } \mathrm{D}_{\mathrm{p}}\end{array}$} & \multicolumn{3}{|c|}{ Trailing Distance, $\mathbf{L}_{\mathbf{T}}$} \\
\hline & & & & $\begin{array}{l}\text { Behind MDTV } \\
\text { or other }\end{array}$ & $\begin{array}{l}\text { Behind } \\
\text { PCDTV }\end{array}$ & $\begin{array}{c}\text { Behind } \\
\text { PTV/Orion }\end{array}$ \\
\hline & $(-)$ & (ft) & (ft) & (DB range) & (DB range) & (DB range) \\
\hline FBCP & 12 & 7.00 & 4.90 & $43.6-62.8$ & $10.3-10.3$ & $5.5-5.5$ \\
\hline Drogue & 24 & 23.00 & $\begin{array}{c}8.73\left(1^{\mathrm{st}}\right) \\
11.59\left(2^{\text {nd }}\right) \\
16.10(\text { full })\end{array}$ & $54.2-54.7$ & $11.2-11.3$ & $6.0-6.1$ \\
\hline Pilot & 12 & 9.85 & 6.90 & N/A & $7.7-7.7$ & $4.1-4.1$ \\
\hline Main & 80 & 116.00 & $\begin{array}{c}9.87\left(1^{\mathrm{st}}\right) \\
19.52\left(2^{\text {nd }}\right) \\
81.20 \text { (full) }\end{array}$ & $116.6-119.8$ & $25.6-26.2$ & $13.7-14.0$ \\
\hline
\end{tabular}

American Institute of Aeronautics and Astronautics 
The geometry of a deploying and full open Drogue cluster is shown in Figure 2. Forebody effects are characterized in terms of Pressure Recovery Fraction (PRF), defined as the ratio of dynamic pressure at the canopy, $\bar{q}$, to freestream dynamic pressure, $\overline{\mathrm{q}}_{\infty}$. When a parachute is in a wake, $\mathrm{PRF}<1$. When a parachute is outside of a wake, PRF $=1$.

A generalized PRF wake model for an Orion forebody was developed by Phil Stuart at NASA-JSC using Computational Fluid Dynamics (CFD). ${ }^{9}$ The model was assembled by analyzing detached eddy simulation (DES) Overflow ${ }^{10}$ solutions run by Scott Murman at NASA-Ames. The model consists of a series of look-up tables to determine PRF as a function of Mach number, total angle of attack $\left(\alpha_{\mathrm{T}}\right)$, trailing distance, and projected diameter.

CPAS simulations have transitioned away from the PRF model in favor of estimating wake effects on a statistical basis from the gross trends of different forebodies. The PRF model is still active only for the Pilot parachutes during simulations.

\section{Data Collection and Sharing}

Parachute performance from each test is estimated based on instrumentation and trajectory reconstructions. The CPAS flight test reconstruction process for loads and drag area is described in Ref. 11. Because the load cell instrumentation is known to have errors, drag data are now confirmed with trajectory matching using the Flight Analysis and Simulation Tool (FAST). CPAS currently instruments its test vehicles with the NovAtel SPAN-SE (Synchronized Position Attitude \& Navigation), ${ }^{12}$ which combines GPS readings with an accelerometer housed in an $\mathrm{IMU}^{13}$ into an integrated state solution via a Kalman filter. This provides the basis for the Best Estimate Trajectory (BET). ${ }^{14}$ Measured drag areas are often scaled by a few percent in order to match the independent altitude and dynamic pressure data. It is usually possible to match the altitude to within a foot by the end of a parachute phase, as illustrated by the CDT-3-5 Drogue phase reconstruction in Figure 3. This ensures a high degree of accuracy in the drag data used to estimate wake effects.
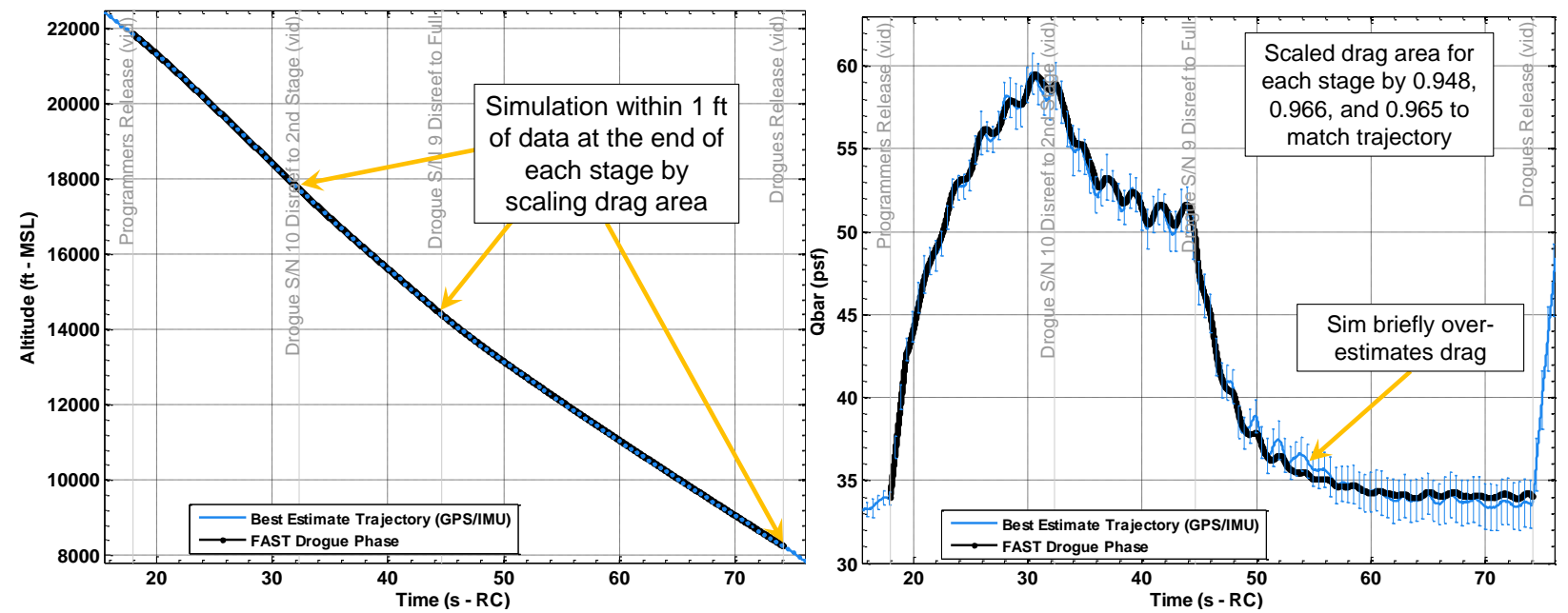

Figure 3. FAST reconstruction of CDT-3-5 Drogue phase (black) to match trajectory data (blue).

A summary of all the relevant CPAS flight test reconstructions to date is presented in Table 2. Some early singlecanopy flights in the Drogue Development Test (DDT) series and Main Development Test (MDT) series estimate drag using exclusively MATLAB optimization code (orange) while almost all CDT flights are reconstructed using FAST (green), which includes trajectory matching. The only data from weight tub tests still included are from Gen II Mains 
with the added porosity design, where the parachutes which are considered too large to be significantly affected by the platform wake. The number of individual canopies reconstructed should provide a sufficient quantity to perform statistical analyses.

Table 2. Summary of CPAS Inflation Reconstructions

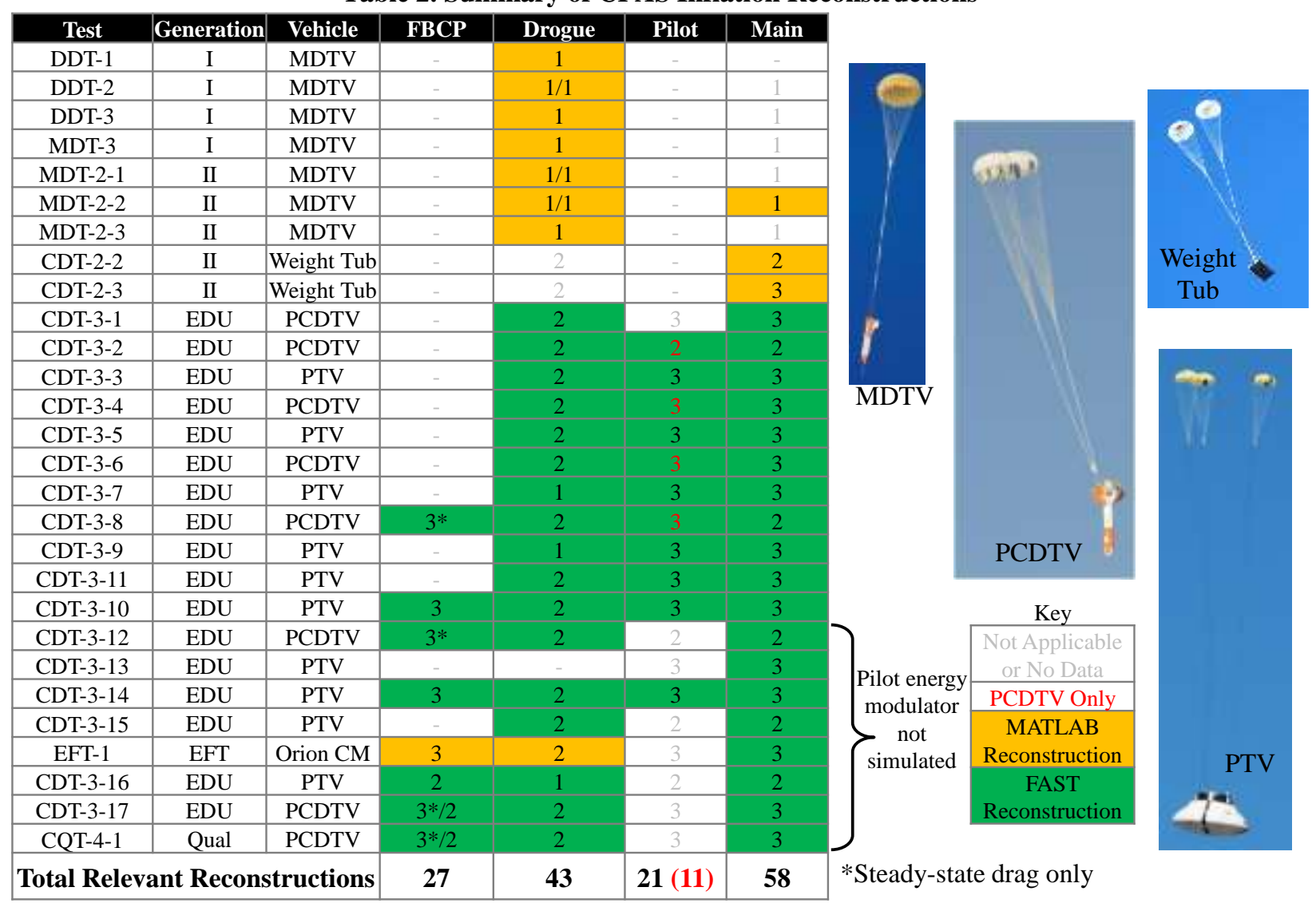

In order to take full advantage of reconstructed flight test data, the results from analogous parachutes are often shared. Figure 4 shows a flow diagram for how reconstructed data are assembled into probability distributions. These distributions are used to create dispersed inputs for Monte Carlo simulations, as explained in Ref. 15. Distributions relevant to the Orion MPCV are collected in the CPAS Model Memo ${ }^{16}$ (green), while distributions for use in planning flight tests are collected in the CPAS Test Technique Memo ${ }^{17}$ (blue).

American Institute of Aeronautics and Astronautics 


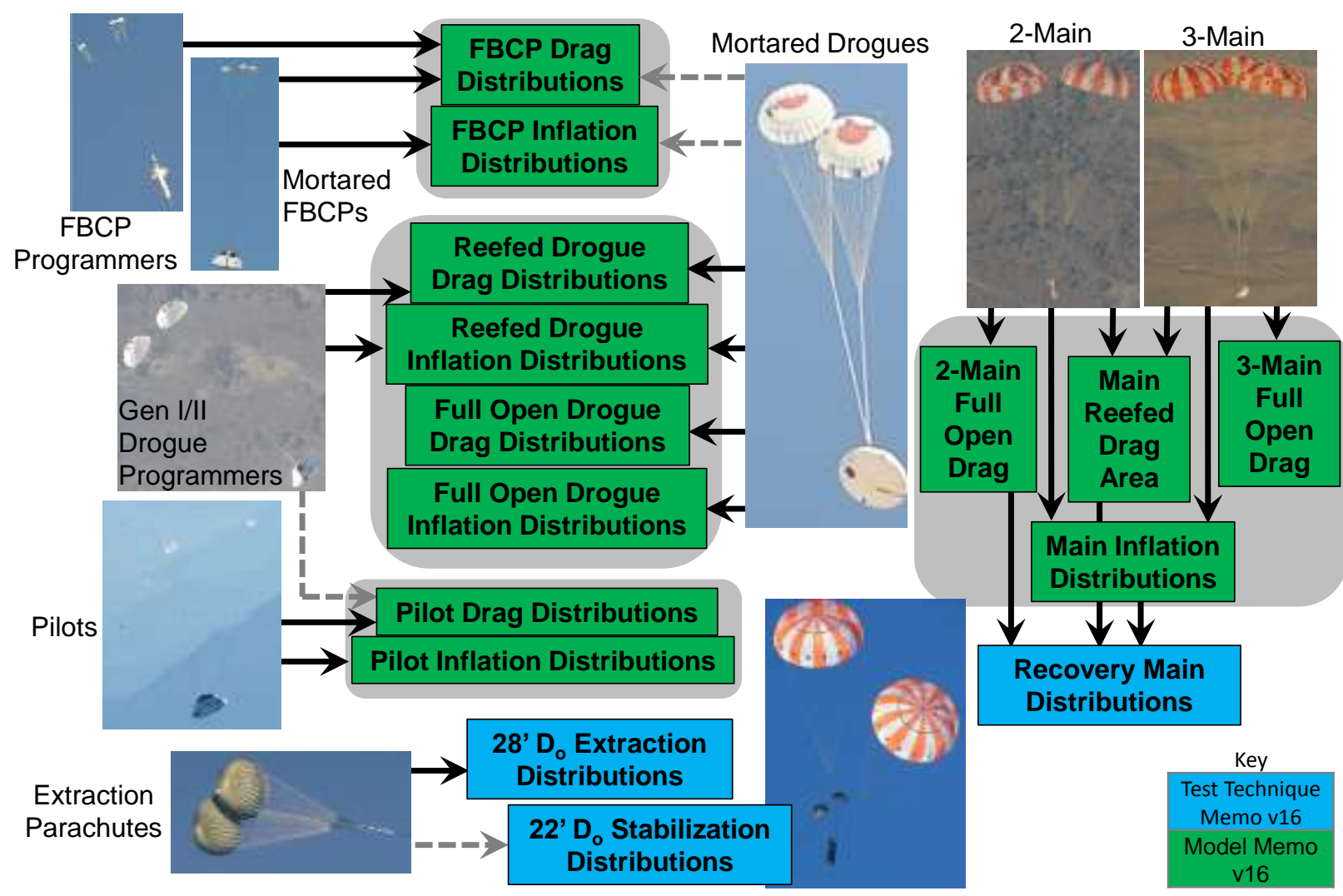

Figure 4. Reconstructed Test Data Flow.

The sharing of data is most significant for the FBCPs, which were not extensively flight tested until mid-way through the program. Both the FBCP and EDU Drogue designs have an $\mathrm{L}_{\mathrm{s}} / \mathrm{D}_{\mathrm{o}}$ ratio of 2.0. Therefore, much of the FBCP drag area distribution was determined by scaling full open EDU Drogue drag area data according to Eq. 1.

$$
\left(C_{D} S\right)_{\mathrm{FBCP}}=\left(C_{D} S\right)_{\text {Drogue }} \cdot \frac{\left(S_{o}\right)_{F B C P}}{\left(S_{o}\right)_{\text {Drogue }}}=\left(C_{D} S\right)_{\text {Drogue }} \cdot \frac{\left(D_{o}\right)_{F B C P}^{2}}{\left(D_{o}\right)_{\text {Drogue }}^{2}}=\left(C_{D} S\right)_{\text {Drogue }} \cdot\left(\frac{7}{23}\right)^{2}
$$

Similarly, few CPAS Pilot data points were able to be reconstructed from flight tests. Therefore, data from the Gen I \& II Drogue data $\left(\mathrm{L}_{s} / \mathrm{D}_{\mathrm{o}}=1.5\right)$ were scaled to be used by the Pilot parachute $\left(\mathrm{L}_{\mathrm{s}} / \mathrm{D}_{\mathrm{o}}=1.15\right)$ according to Eq. 2.

$$
\left(C_{D} S\right)_{\text {Pilot }}=\left(C_{D} S\right)_{\text {Drogue }} \cdot \frac{\left(S_{0}\right)_{\text {Pilot }}}{\left(S_{0}\right)_{\text {Drogue }}}=\left(C_{D} S\right)_{\text {Drogue }} \cdot \frac{\left(D_{0}\right)_{\text {Pilot }}^{2}}{\left(D_{0}\right)_{\text {Drogue }}^{2}}=\left(C_{D} S\right)_{\text {Drogue }} \cdot\left(\frac{9.85}{23}\right)^{2}
$$

Clean wake drag data were also obtained for the FBCP and Pilot at the HIVAS facility at the Naval Air Warfare Center China Lake Weapons Survivability Lab. ${ }^{18}$ However, the FBCP data had large uncertainties due to random oscillation and was therefore removed from the distributions.

\section{Forward Bay Cover Parachutes}

The CPAS FBCPs are designed to safely prevent re-contact between the Forward Bay Cover (FBC) and MPCV after jettison. This capability was demonstrated on CDT-3-10 and CDT-3-14. FBCPs were used as programmers for the PCDTV for much of the EDU test program. Starting with CDT-3-16, two FBCPs were mortar-deployed from the tunnel in order to obtain relevant inflation data on tests without an FBC. The static-line programmer deployment and mortar-deployed FBCP handoff for CDT-3-17 are shown in Figure 5.

American Institute of Aeronautics and Astronautics 


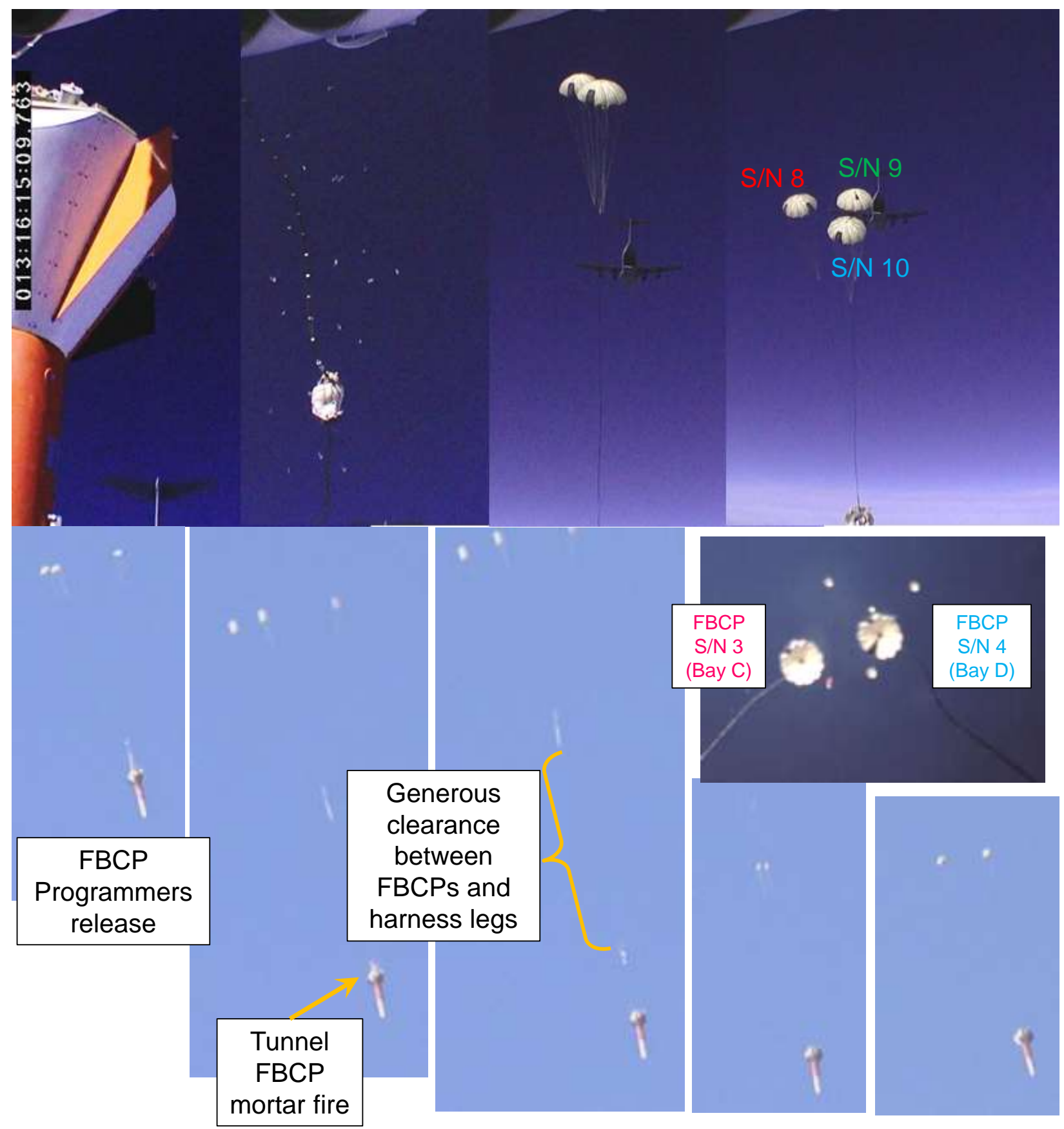

Figure 5. CDT-3-17 Static line deployment of FBCPs-as-programmers (top) and mortar-deployed FBCPs (bottom).

The configurations flown to obtain direct or proxy FBCP drag data are listed according to expected wake effects in Figure 6. The sources range from single canopy drop tests behind a minimal payload (left) to actively using FBCPs to remove the $\mathrm{FBC}$ from the Orion Crew Module (CM) in flight (right). 


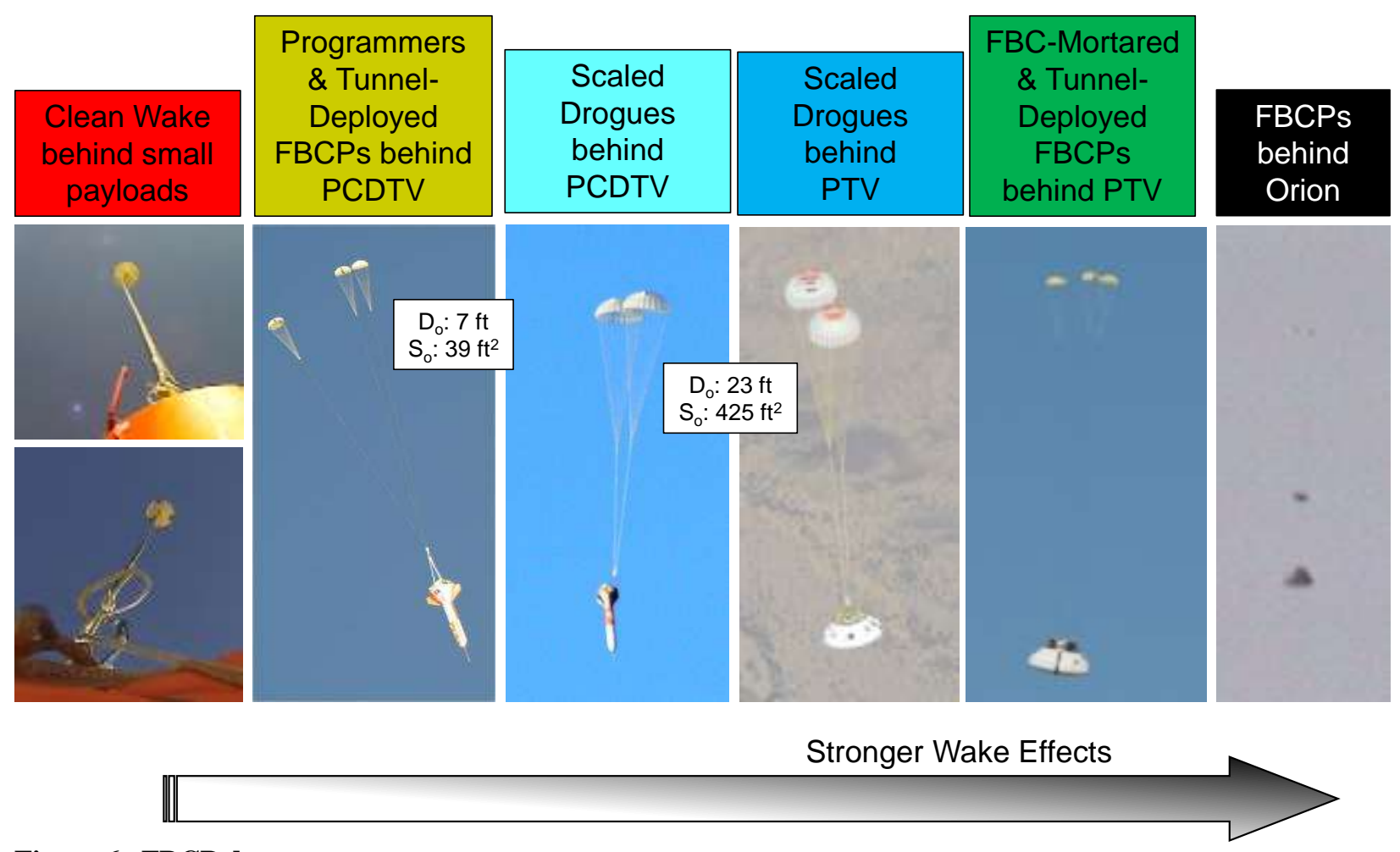

Figure 6. FBCP data sources.

The only Orion flight to date is Exploration Flight Test (EFT)-1. Parachute drag measurements from EFT-1 were lower than from PTV boilerplate tests. This may be partially because the Orion CM is more stable than the PTV, both due to aerodynamics and via active control. The PTV experiences more oscillations and has a shorter height than the Orion CM, so the PTV will therefore present a smaller wake on average. Because there is not yet a statistically significant amount of Orion parachute data to evaluate these effects, the PTV is considered to generate an equivalent "capsule" forebody wake.

The upper histogram of Figure 7 plots all the measured FBCP drag from all the above data sources. The X-axis plots the measured drag area in the presence of various wakes (e.g. the quantity PRF. $C_{D} S$ ) and the $Y$-axis plots the number of test data points. The drag is noticeably lower when behind forebodies with a significant wake and higher in a "cleaner" wake. The data were fit with a normal distribution (dashed curve). In order to normalize the distribution to a PCDTV, each data point was multiplied by the ratio of the mean drag for the given forebody to the mean PCDTV drag, as if the various data were collected in the presence of the PCDTV forebody. The new distribution is shown in the middle histogram, and is not much different than the original histogram. This distribution is used for pre-flight simulations of PCDTV tests. Because the Model Memo is ultimately intended for use with the Orion MPCV, a similar method was used to normalize to a capsule wake, as shown in the bottom histogram. This PTV distribution has a lower mean and narrower standard deviation than before wake normalization.

American Institute of Aeronautics and Astronautics 

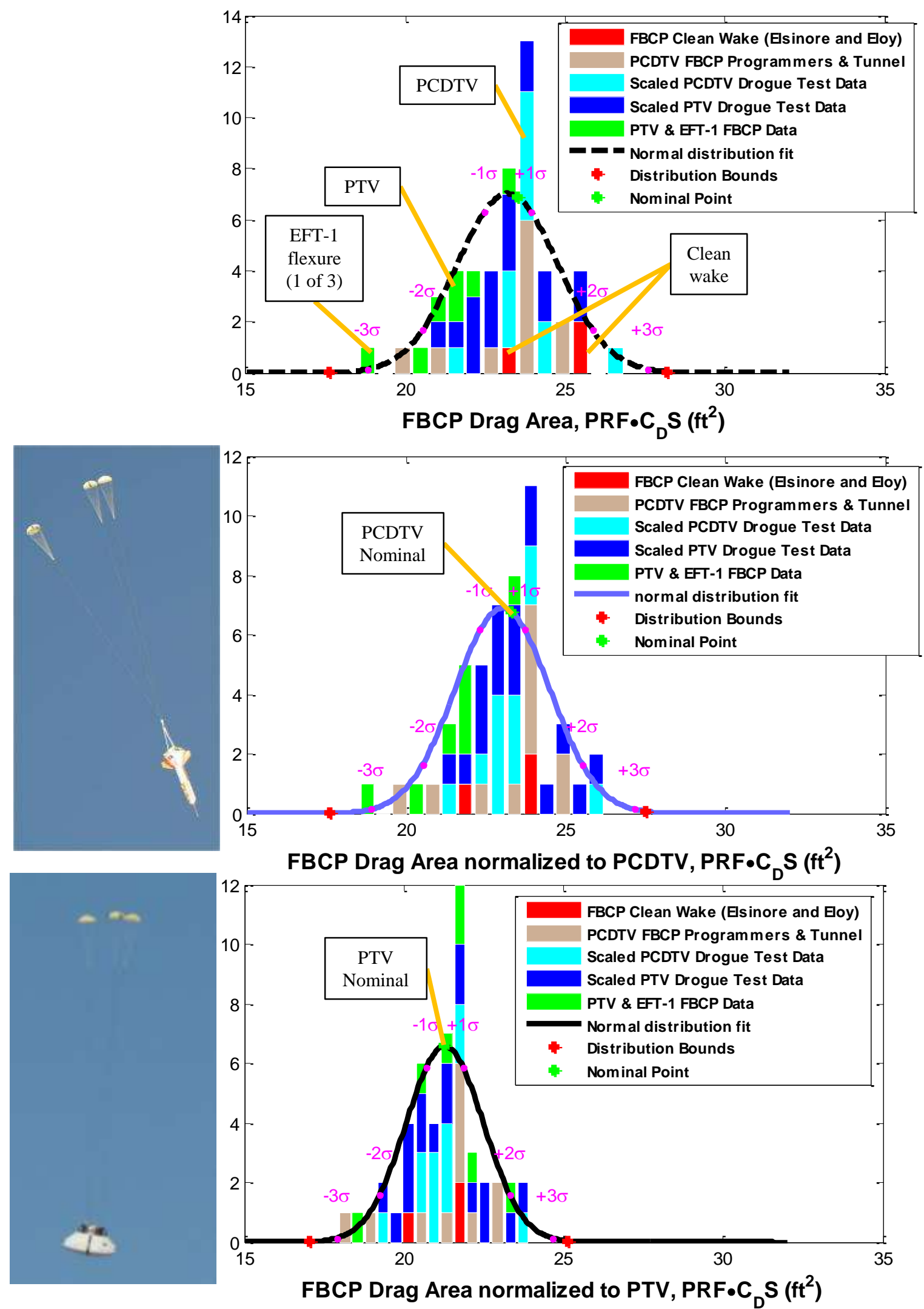

Figure 7. FBCP drag area data (top), normalized to PCDTV (center), or PTV boilerplate (bottom).

American Institute of Aeronautics and Astronautics 


\section{Drogue Parachutes}

Like the FBCPs, wake effects on Drogue drag performance vary with different forebody shapes, as illustrated in Figure 8. The MDTV is used as a baseline for determining PRF by assuming a clean wake. Because the heatshield generates a larger wake than the PCDTV, Drogue drag data behind a capsule will tend to have lower readings.

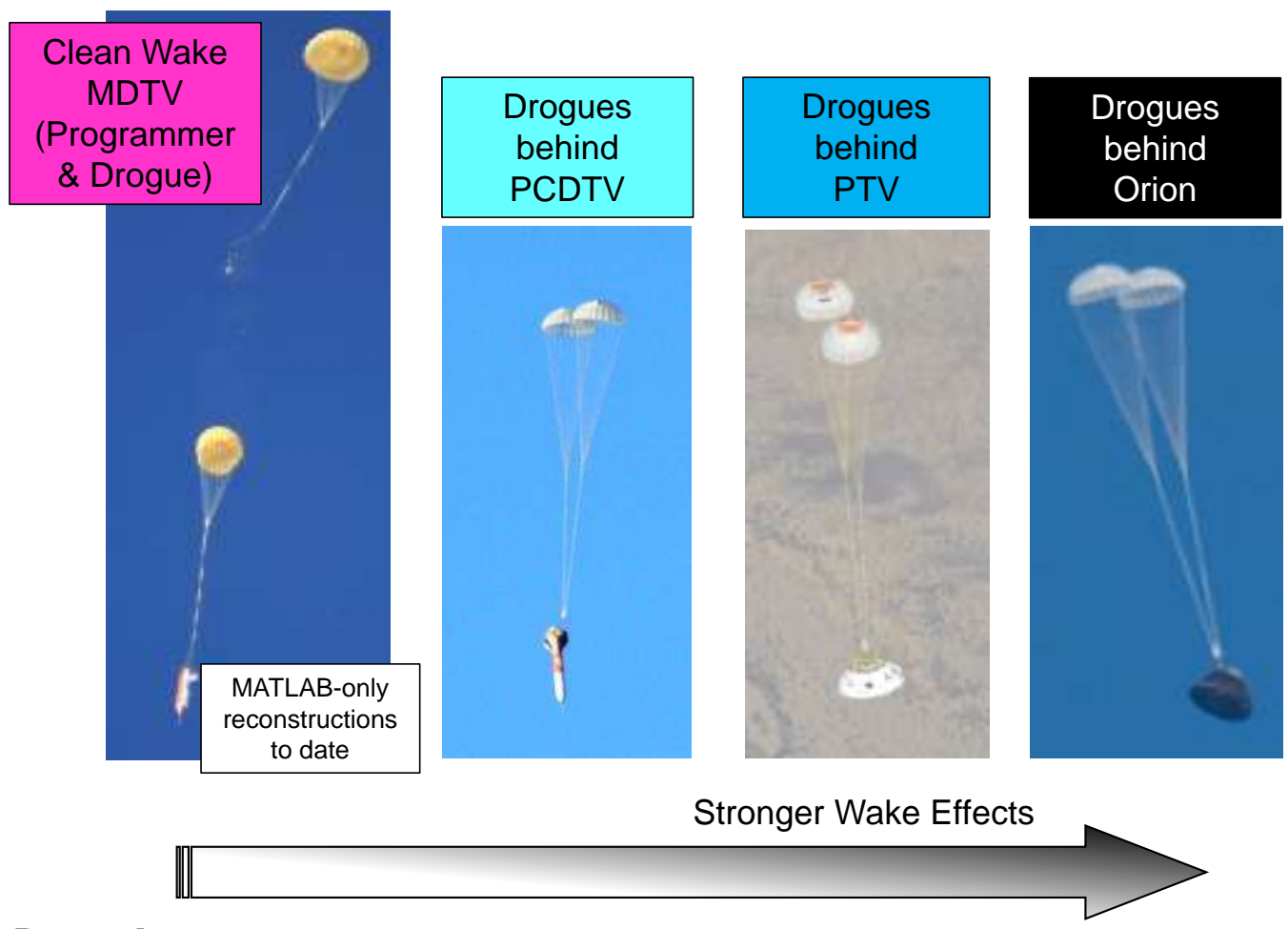

Figure 8. Drogue data sources.

CPAS Drogue reefing line lengths have changed over the course of the program as more flight test data were collected and have converged to 329 and 437 inches for the first and second stage lines, respectively. Because reefed inlet size is determined by the reefing line length, it is assumed that reefed Drogue data from all designs can be used to determine drag trends for the current design, once forebody wake effects are accounted for. However, the $\mathrm{L}_{s} / \mathrm{D}_{\mathrm{o}}$ ratio has increased from 1.5 to 2.0 for EDU, as illustrated in Figure 9. This has a tendency to increase full open drag area since the skirt is slightly more open. Therefore, only full open data with the current design are used in the full open drag area distribution. 

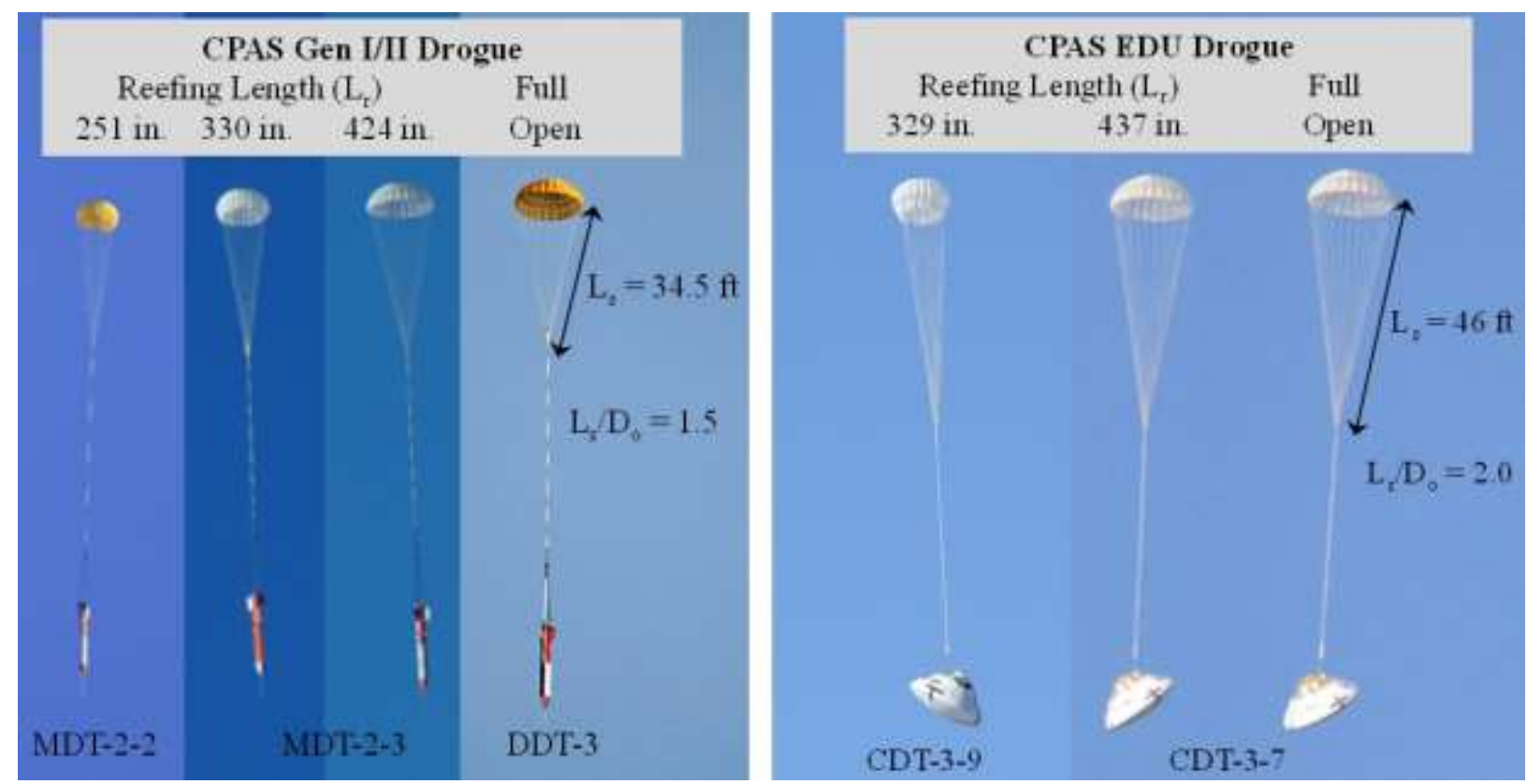

Figure 9. Reefing and suspension line length changes from Gen I/II to EDU Drogues.

The measured reefed drag areas with wake effects, PRF. $\left(\mathrm{C}_{\mathrm{D}} \mathrm{S}\right)_{\mathrm{R}}$, are plotted as a function of geometric reefing area in Figure 10. Data from LVAD platform tests and Pad Abort-1 (PA-1) have been excluded because the data were limited and/or of low quality (e.g. in a turbulent platform wake). The upper plot characterizes reefing in terms of projected reefed area, $S_{R}$, resulting in linear trends. Data from early tests using the MDTV are considered to be "clean wake" data. Tests from PCDTV and PTV are plotted separately. Three trend lines were produced based on the different forebody wakes, yet the lines are all nearly parallel. As expected, the trend from the PTV is lowest, because a capsule generates the strongest wake. It was somewhat surprising that the PCDTV trend line is nearly coincident with that of the "clean" wake of the MDTV. Either the MDTV generates a non-trivial wake or PCDTV wake effects on Drogues are less significant than expected. The ordinates corresponding to the desired reefed areas on the PTV trend-line are used to determine the nominal reefed drag areas for each reefed stage. The offset of each data point from its corresponding trend-line is used to determine the reefed drag area distributions.

The lower plot normalizes reefed diameter $\left(D_{R}\right)$ by reference diameter to compute geometric reefing, $\tau$, resulting in quadratic trends. Drag is normalized according to the average full open drag for each forebody, $\left(\mathrm{C}_{\mathrm{D}} \mathrm{S}\right)_{\mathrm{o}}$, to compute the reefing ratio, $\varepsilon$. This traditional formulation of reefed performance has the disadvantage of indirectly relying on full open performance, even for tests with never fully disreef, potentially compounding measurement errors. This formulation has the effect of separating the clean wake trend from the PCDTV trend because MDTV tests used Gen I/II Drogues with lower full open drag, increasing the resulting $\varepsilon$ calculations. For these reasons, CPAS databases and simulations have completely transitioned to representing drag in terms of drag area instead of reefing ratio.

American Institute of Aeronautics and Astronautics 

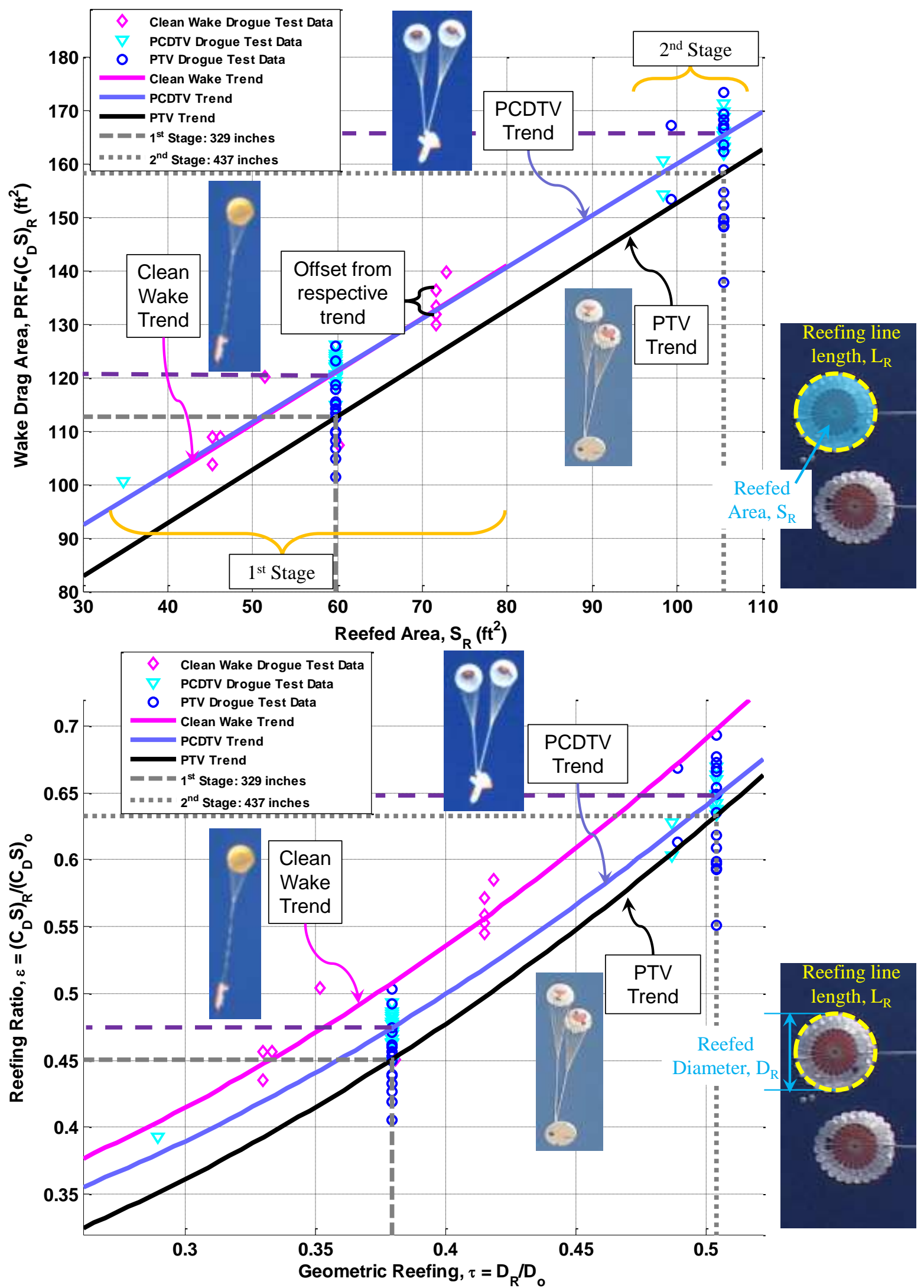

Figure 10. Plotting Drogue reefed drag area for different forebodies in terms of reefed area results in linear trends (top) while plotting in terms of reefed diameter results in quadratic trends (bottom).

American Institute of Aeronautics and Astronautics 
A comparison of the wake effects during Drogue first stage are shown in Figure 11. The top histogram shows all the original reefed drag data, which indicate multiple modes. Scale factors were then applied to the data to determine drag area distributions normalized to both a PCDTV and capsule forebody wake. The PCDTV-normalized distribution is shown in the center. The distribution normalized to a PTV wake is shown in the lower histogram. As with the FBCP distributions, the PTV wake moves the center of the distribution to a lower value and reduces the standard deviation.
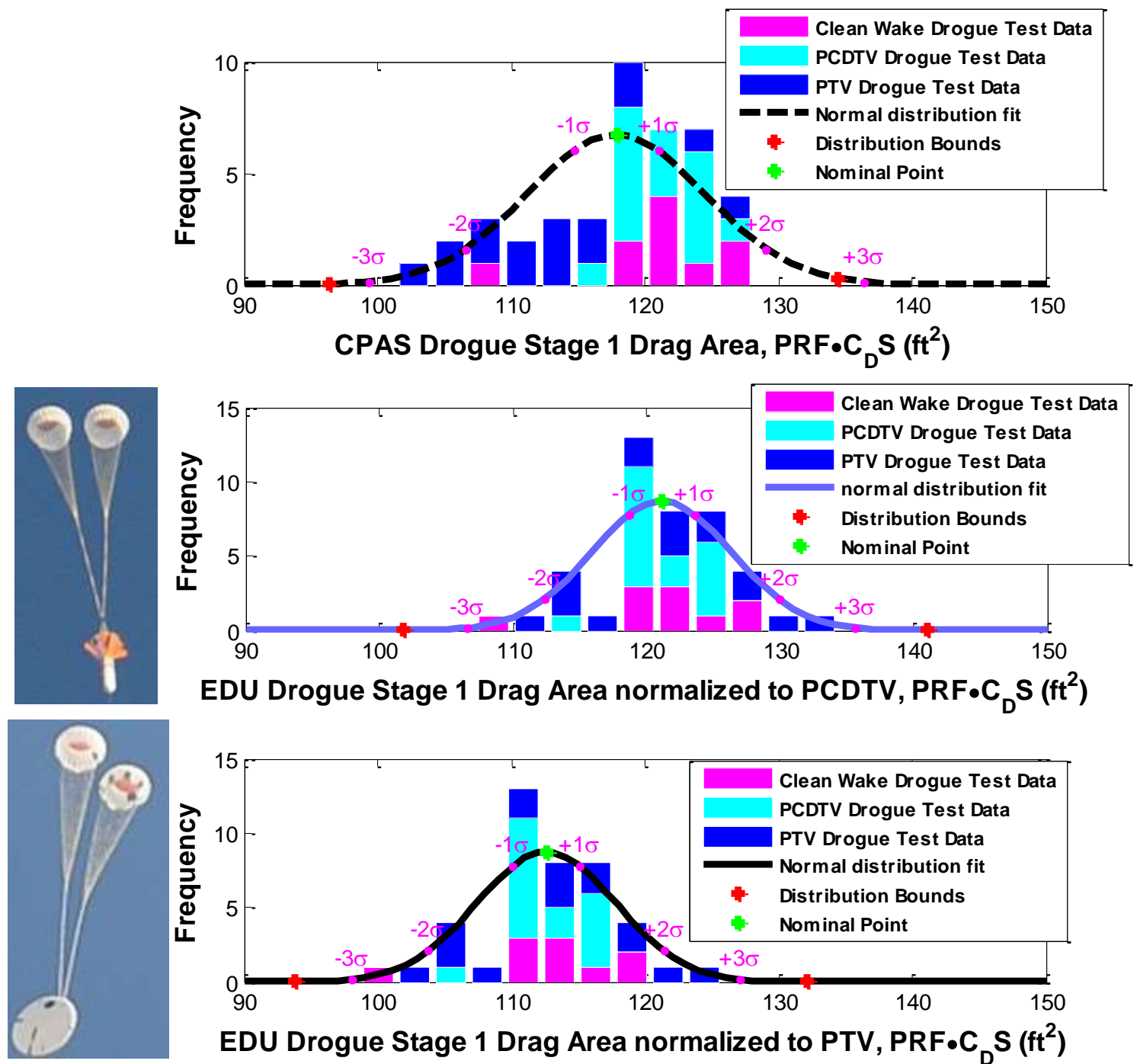

Figure 11. Drogue $1^{\text {st }}$ stage drag area original data (top), normalized to PCDTV (center), and normalized to PTV boilerplate (bottom).

The second stage original data and normalized distributions are shown in Figure 12. The change in distributions is not as large as for the first stage. 

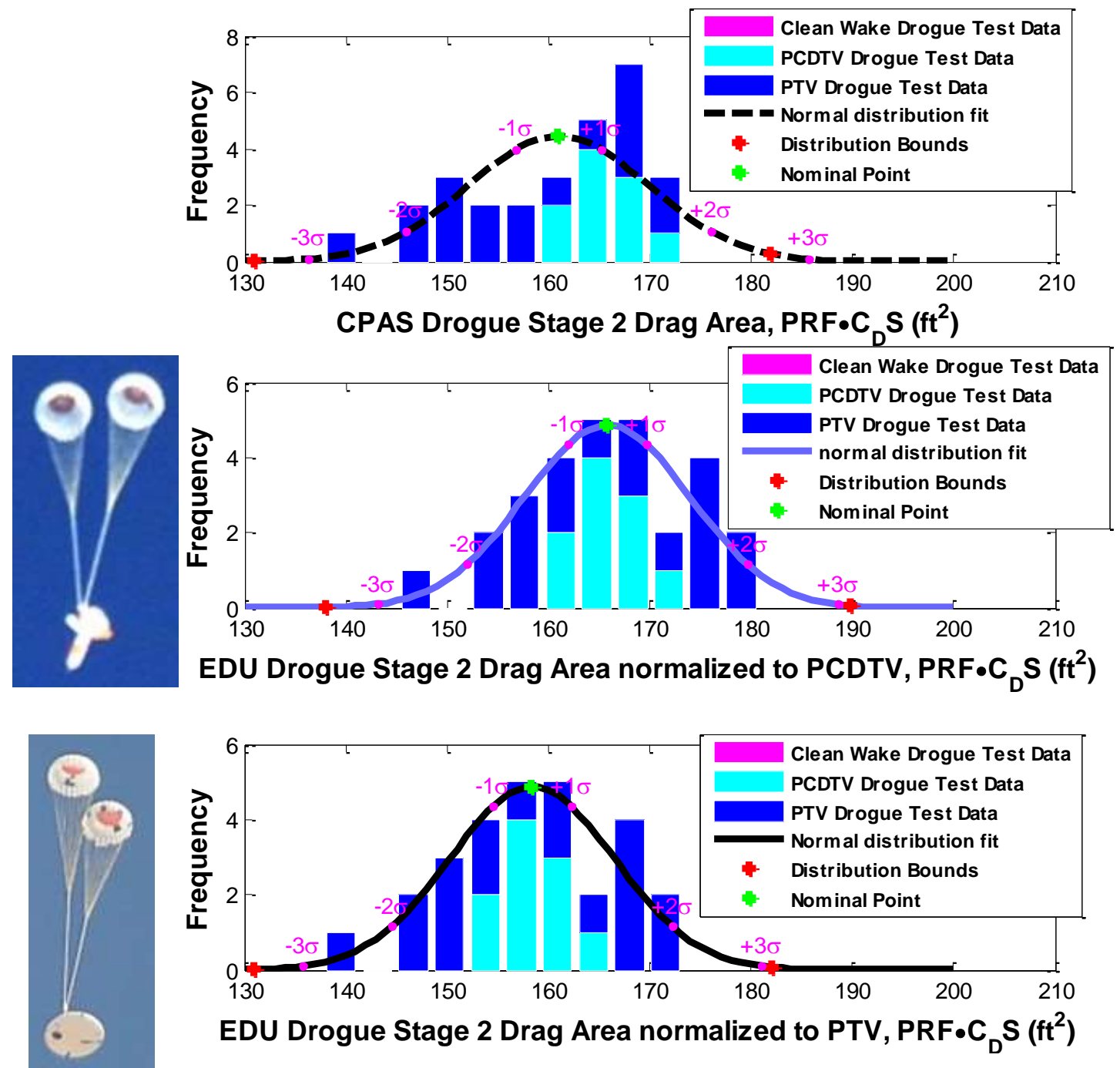

Figure 12. Drogue $2^{\text {nd }}$ stage drag area original data (top), normalized to PCDTV (center), and normalized to PTV boilerplate (bottom).

The forebody effects on full open Drogue data are shown in Figure 13. Note that the amount of scaling applied to the original data decreases with each stage. This is because the wake effects are lessened as the canopy projected area gets larger relative to the forebody. 

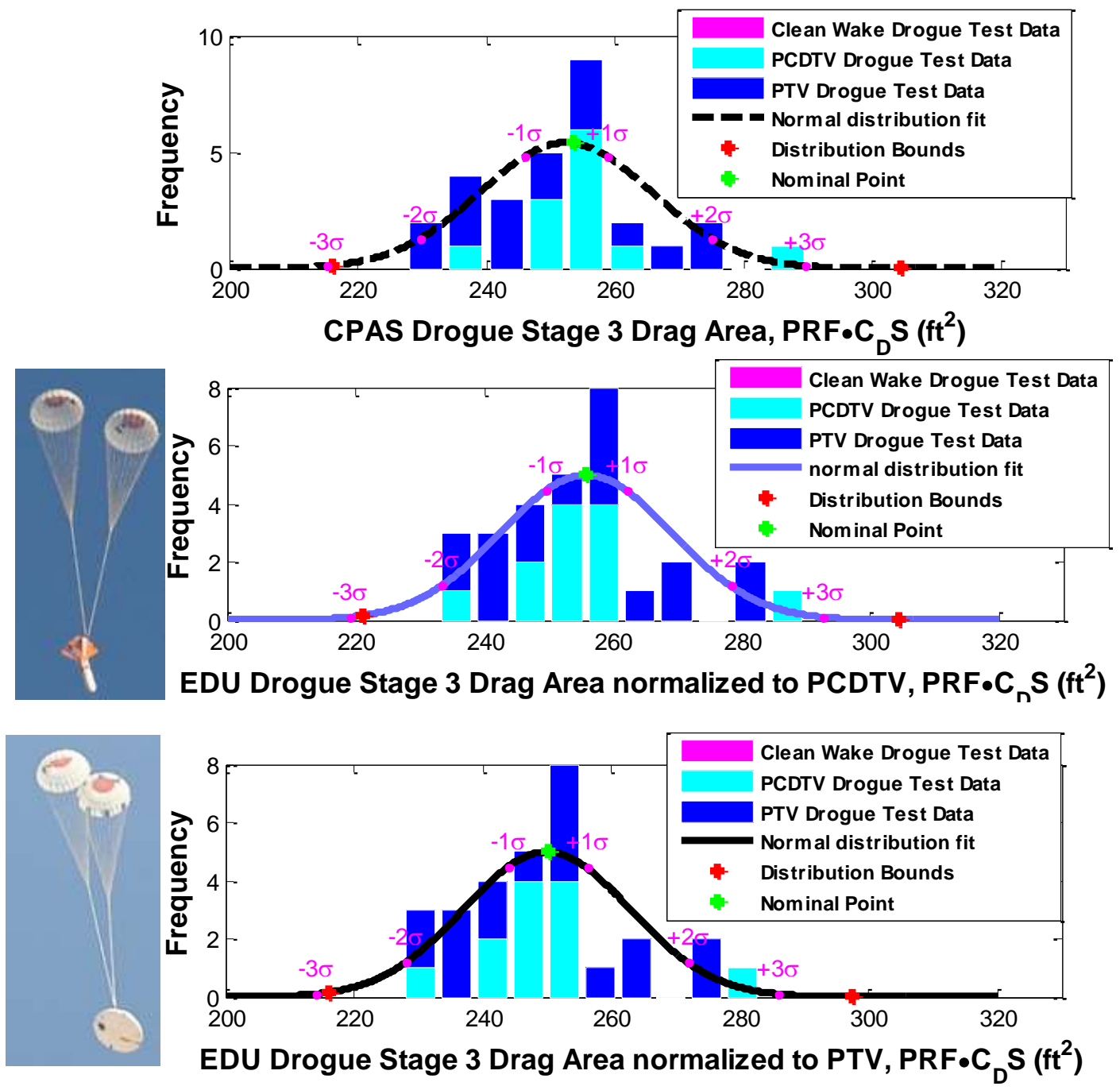

Figure 13. Drogue full open drag area original data (top), normalized to PCDTV (center), and normalized to PTV boilerplate (bottom).

\section{Pilot Parachutes}

Each Pilot parachute lifts and deploys a corresponding Main canopy. The Pilots are the only parachutes for which the wake model is active in FAST simulations. The Orion wake model was developed using CFD by analyzing the flowfield behind the MPCV for a series of Mach numbers and angles of attack. That model assumes that each parachute is centered at the strongest part of the wake at each trailing distance, so the effective PRF is probably lower than reality. A sample CFD flowfield for PRF calculation is illustrated in Figure 14. A given Pilot parachute is especially unlikely to be located at the minimal PRF coordinate because the Pilots are mortared out nearly perpendicular to the velocity vector and the cluster tends to remain spread out. Therefore, the reconstructed Pilot drag areas from PTV tests are probably larger than actual freestream performance in order to compensate for the conservatism in the model. 


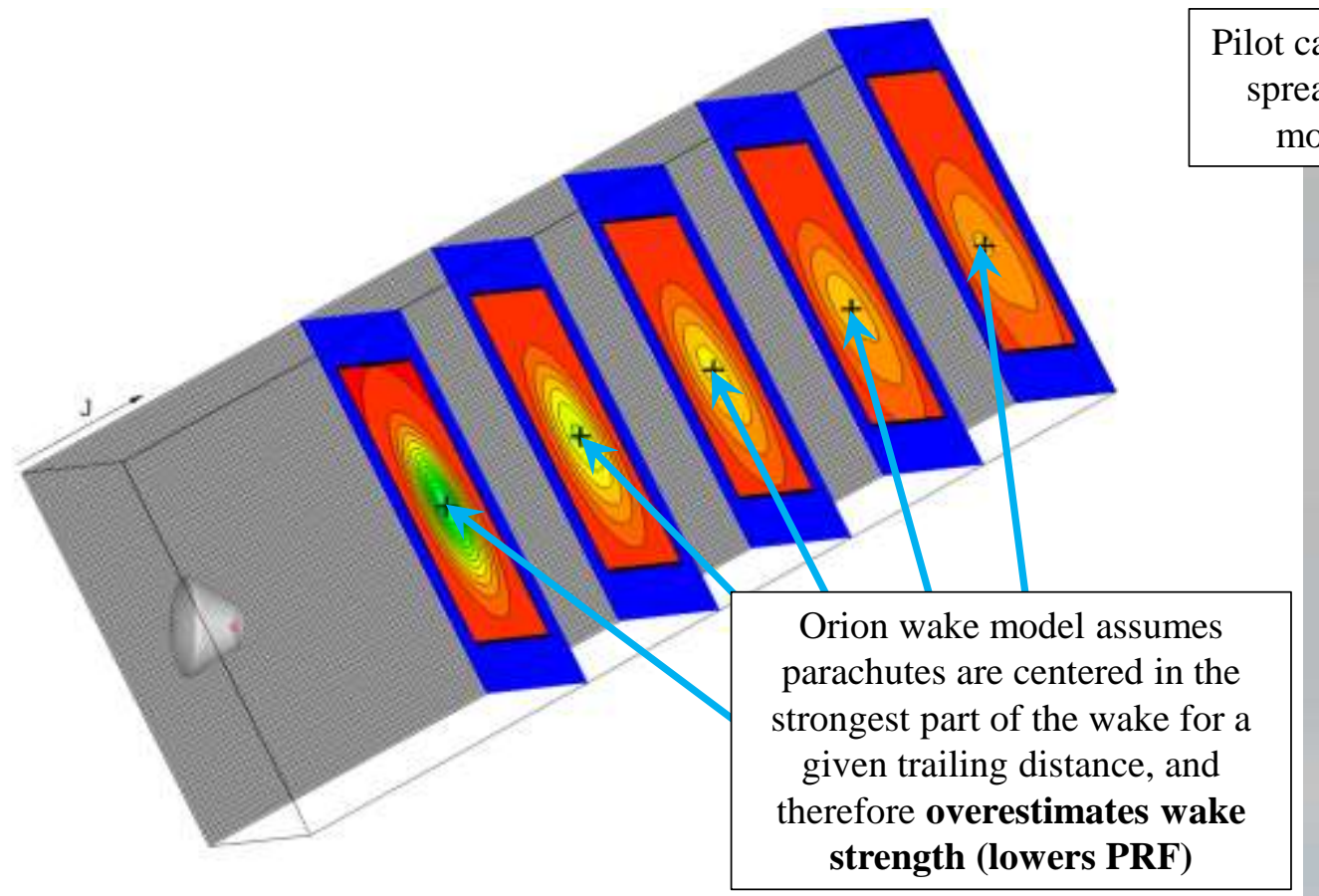

Pilot canopies are more spread out than the model assumes

Figure 14. Determination of final PRF values in MPCV wake.

Meanwhile, FAST simulations of PCDTV tests assume no wake (PRF $=1.0)$. In reality, the PCDTV has a forebody diameter of about $8.8 \mathrm{ft}$ and must therefore generate a non-trivial wake, especially for small parachutes such as Pilots. In order to reconstruct a particular PCDTV test, FAST will generally use a Pilot drag area lower than the assumed freestream value.

The Pilot drag area values from all sources are plotted in the top histogram of Figure 15. The reconstructed PCDTV Pilot drag area data are lower than those from PTV reconstructions and "clean" wake sources by about $78 \%$. The PCDTV-specific distribution is shown in the middle plot. This distribution is centered on the average of the PCDTV reconstructed data. Using a similar scaling method as other parachutes, all the other data were scaled according to the average of each respective source to the PCDTV average. The distribution for use with a PTV was generated by omitting the PCDTV data, and is shown in the bottom plot. Determining average PRF for the Pilots in the PTV wake would require reconstruction without the wake model. This may be attempted in the future using a dedicated finite element line sail model.

American Institute of Aeronautics and Astronautics 

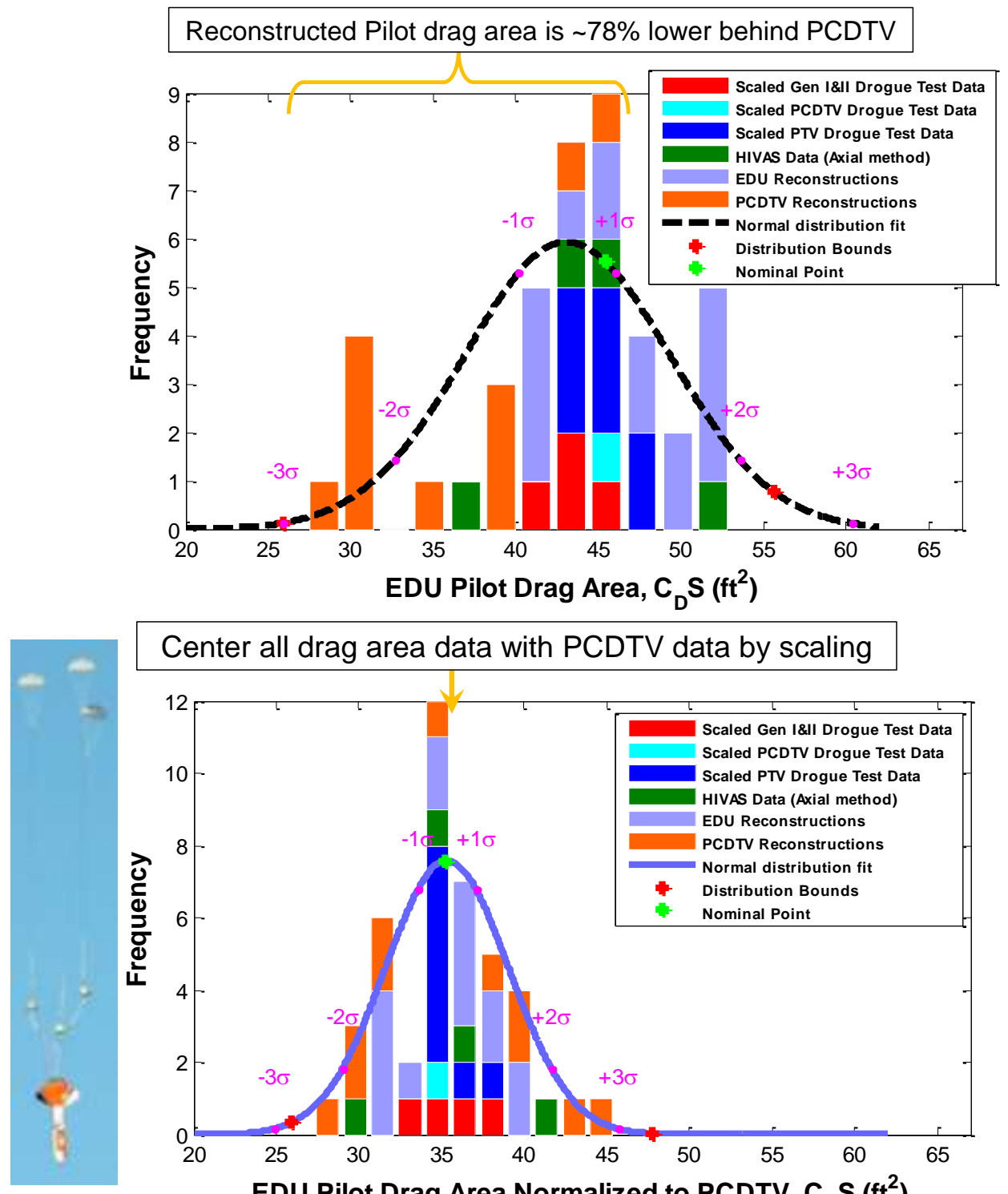

\section{Center all drag area data with PCDTV data by scaling}
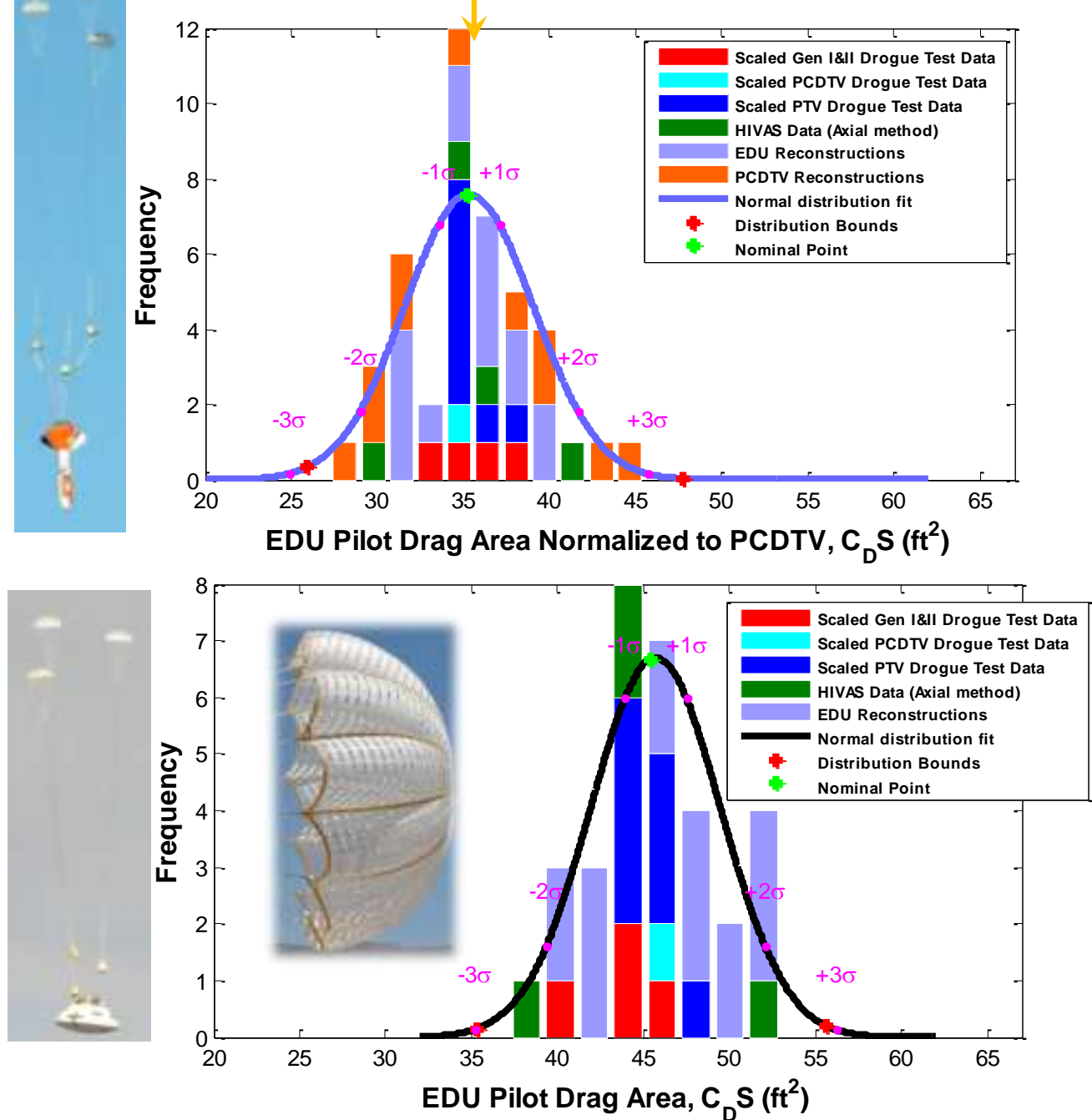

Figure 15. Pilot drag area for all data (top), PCDTV (center), and PTV and clean wake (bottom).

American Institute of Aeronautics and Astronautics 


\section{Main Parachutes}

Evaluating forebody effects on Main parachutes presents difficulty due to the number of degrees of freedom. Main canopy porosity, suspension line length ratio, and reefing line lengths have changed over the course of the program. In addition, some tests were conducted to simulate parachute-out and skipped stage conditions, reducing the sample size for a given configuration.

A close examination of test reconstructions uncovered a forebody effect on the Mains during the first stage, when their size is the smallest. From the definition of PRF, it is known that a larger wake will lower the local airspeed experienced by the inflating canopy. However, inflation data are normalized according to the measured airspeed of the test vehicle, since it is not possible to measure airspeed at the canopy. This leads to a bias where the computed fill constant (n) is lower in a PCDTV wake than a stronger capsule wake, as shown for the Main first stage inflation parameters in Figure 16. The resulting distributions, shared by both test vehicles, should be conservative, because lower fill constants tend to cause higher predicted inflation loads.
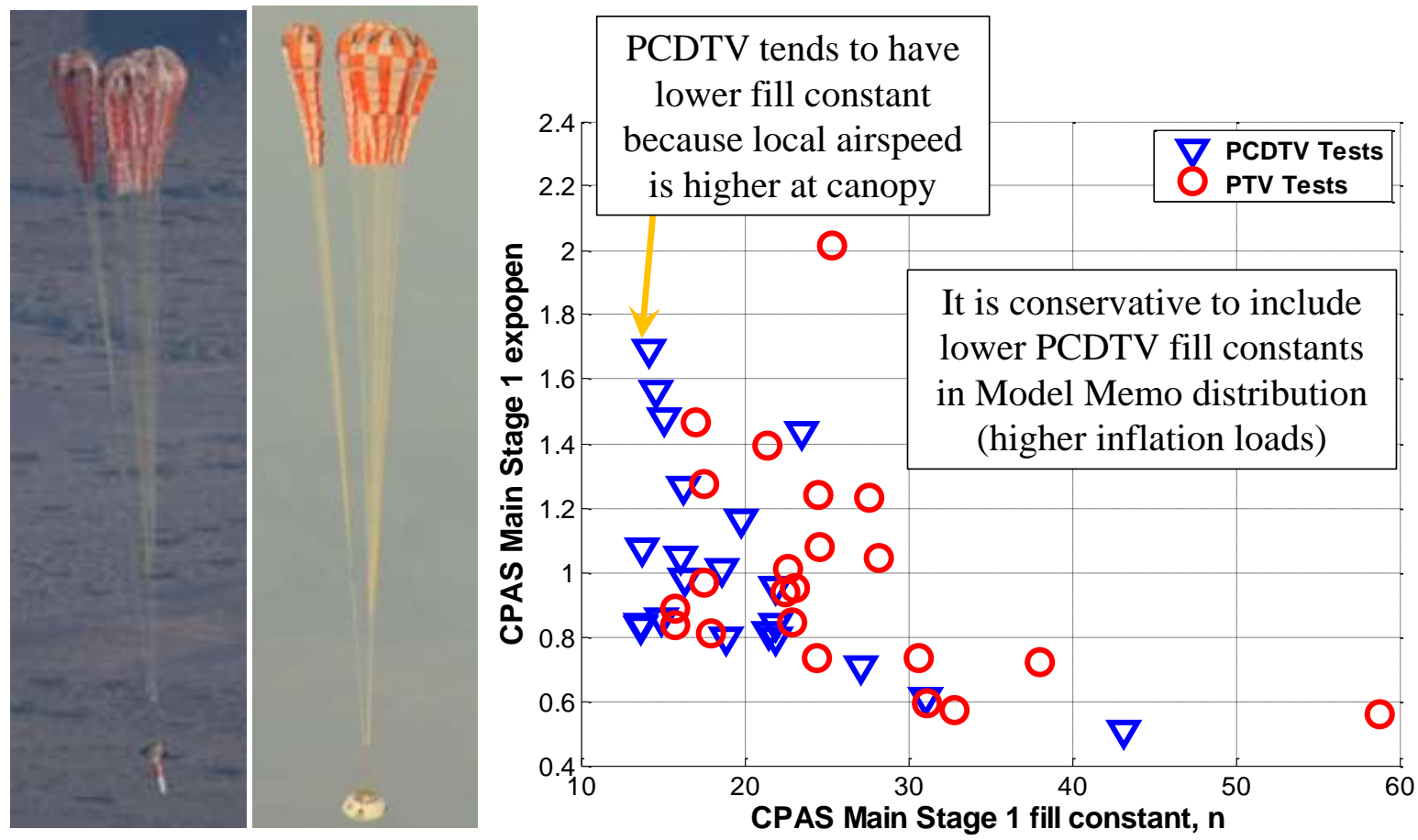

Figure 16. Main $1^{\text {st }}$ stage forebody effects on inflation exponential term (expopen) and fill constant (n) parameters.

Reconstructions of Main parachute drag do not show significant differences between PTV and PCDTV tests. Therefore, PCDTV simulations use the same distributions as the PTV for simulating the Main phase. By the time of full open, the size of the canopies makes any forebody wake effect negligible. Flight simulations hand off to either the CPAS symmetric time-varying rate of descent mode ${ }^{19}$ or the independent canopy model used to evaluate pendulum effects, ${ }^{20}$ neither of which account for forebody effects.

It has been established that the number of parachutes in a cluster $\left(\mathrm{N}_{\mathrm{c}}\right)$ has a more significant effect on reefed performance than the type of forebody. Mutual aerodynamic interference between canopies causes an elongation of the inlet, which affects tension in the suspension lines ${ }^{21}$ and reefing lines. ${ }^{22}$ The reefed performance for clusters of one, two, and three CPAS Main parachutes are plotted in Figure 17. While a single canopy is the most efficient with the highest drag, a cluster of two actually generates less drag per canopy than a cluster of three. This is because for a fixed inlet perimeter $\left(\mathrm{L}_{\mathrm{r}}\right)$, a circular inlet provides the most inlet area. Clusters of two tend to have oblong inlets parallel to each other while clusters of three tend to spread out further with less distorted inlet geometry. As with the Drogues, plotting in terms of reefed area results in linear trends, as shown in the upper plot. The lower plot puts the reefed drag performance in terms of $\varepsilon$ vs. $\tau$, resulting in quadratic trends.

American Institute of Aeronautics and Astronautics 

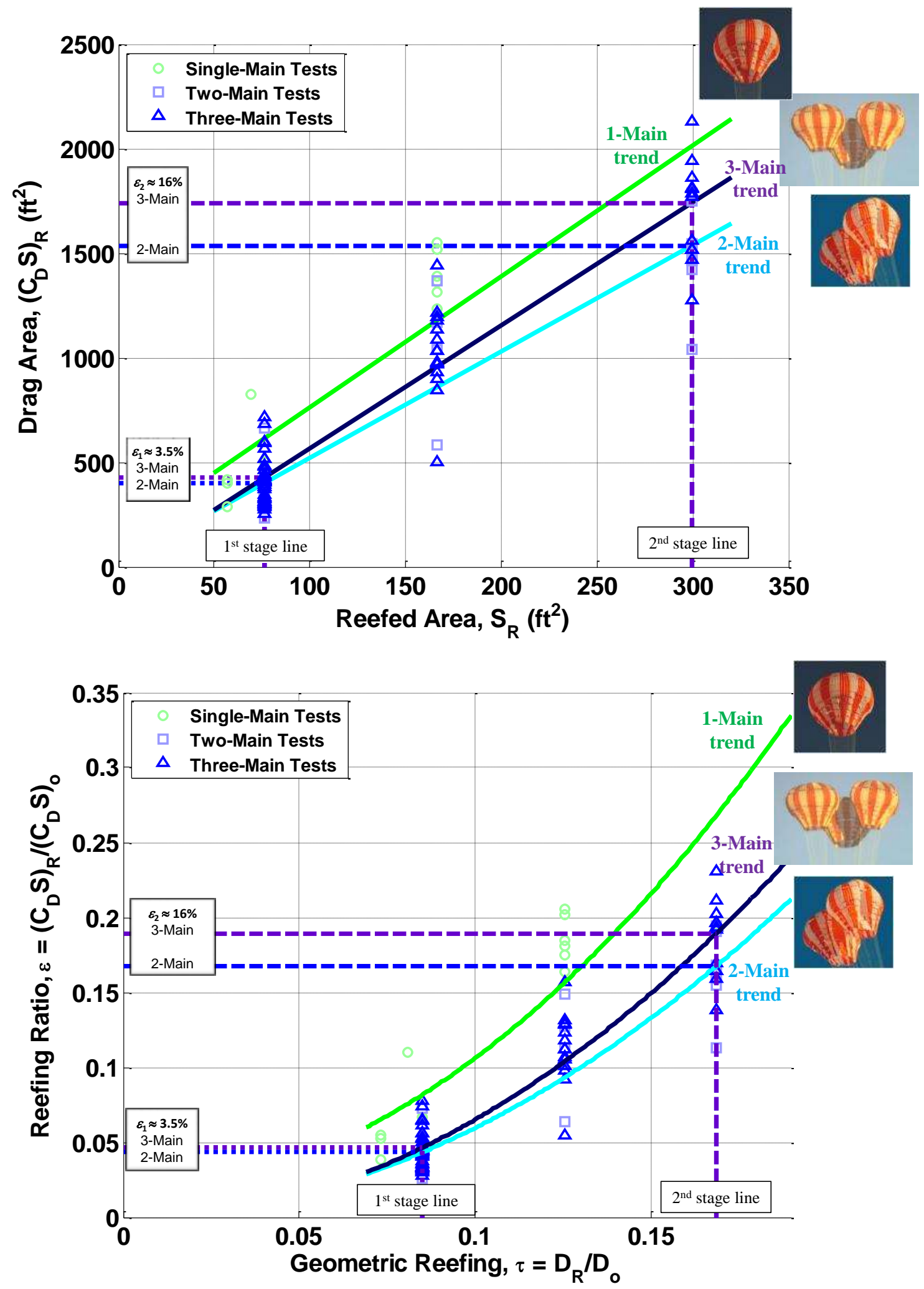

Figure 17. Main reefed drag area trends according to number of canopies. Drag area vs. reefed area results in linear trends (top) while reefing ration vs. geometric reefing results in quadratic trends (bottom). 


\section{PRF Calculations \& Summary}

A traditional representation of wake performance is to plot drag coefficient loss in terms of trailing body diameters. Drag coefficient loss can be considered equivalent to PRF. Figure 18 is a re-creation of Fig. 5-21 in Ref. 6 which plots legacy wake data from Apollo flight tests and other programs. This chart was augmented with recent wind tunnel test data obtained on behalf of the Orion program. A NASA/academic partnership tested a 10\% scale fabric Drogue behind an Orion heat shield model in the Texas A\&M (TAMU) Oran W. Nicks subsonic wind tunnel $\left(10^{\prime} \times 7^{\prime}\right) .{ }^{23}$ Although there is some test-to-test variation in the data (plotted in red) due to various factors (model angle of attack, number of canopies, and reefing), the average is well within the envelope of legacy data. The US Air Force Academy (USAFA) used a $3^{\prime} \times 3^{\prime}$ subsonic wind tunnel to investigate the effect of an Orion model wake on $2 \%$ scale solid models of the Drogue $^{24}$ (plotted in yellow) and Pilot ${ }^{25}$ (plotted in purple). These data are consistent with the trends.

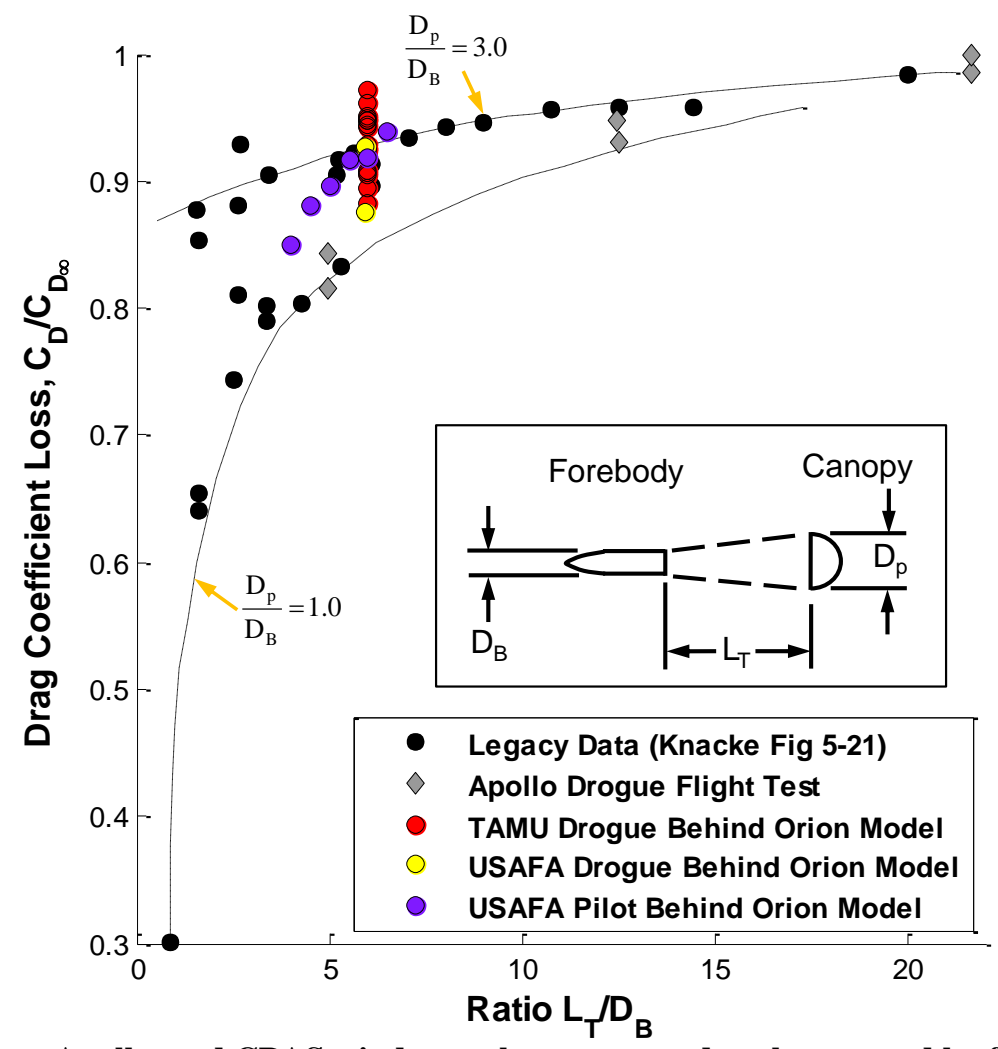

Figure 18. Legacy, Apollo, and CPAS wind tunnel test canopy drag loss caused by forebody wake.

The ratio of mean drag in a particular wake to the mean of clean wake drag was used to estimate average PRF for CPAS flight data. These average PRF values are essentially the same as the scale factors used in creating drag area distributions. CPAS flight data were appended to legacy and wind tunnel data in Figure 19. This analysis assumes that the PRF for small test vehicles (such as the MDTV) is 1.0, plotted as horizontal lines at that value. Average computed PRF for each of the canopies behind the PTV and PCDTV are plotted as horizontal lines with heights less than 1.0 and only extending to the largest trailing distance. There is a wide test-to-test variation in wake computations from each source. While much of the test data is outside the legacy envelope, the average PRF values follow the expected trend. This illustrates the need for a sufficient number of tests to generate baseline performance. The PRF values are listed in the legend and summarized in Table 3.

American Institute of Aeronautics and Astronautics 


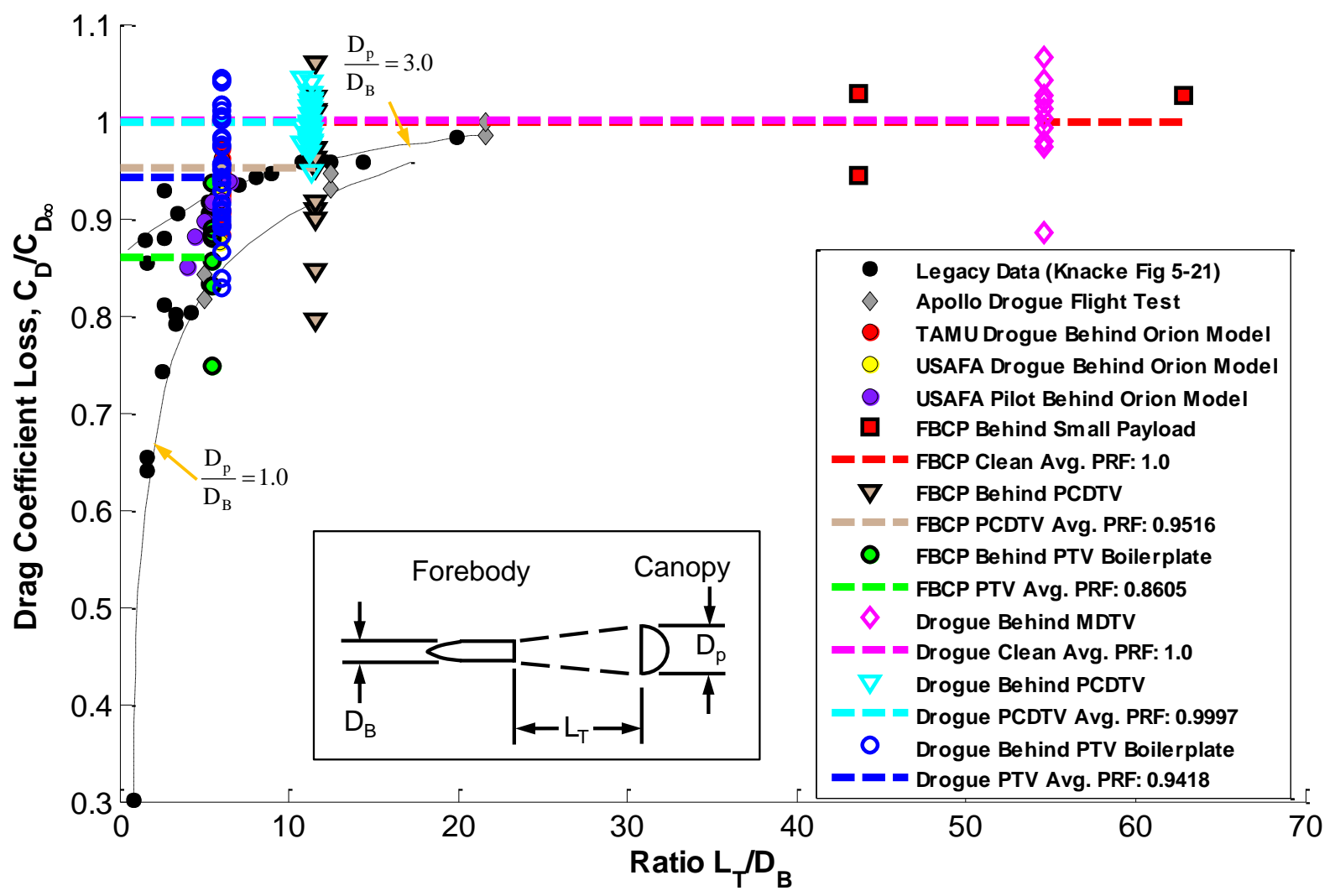

Figure 19. CPAS canopy drag loss caused by forebody wake compared to other data.

Table 3. Summary of CPAS PRF Behind Test Forebodies

\begin{tabular}{|c|c|c|c|}
\hline \multirow[b]{2}{*}{ Parachute } & \multicolumn{3}{|c|}{ Average Pressure Recovery Fraction } \\
\hline & $\begin{array}{c}\text { Behind } \\
\text { MDTV/Clean }\end{array}$ & $\begin{array}{l}\text { Behind } \\
\text { PCDTV }\end{array}$ & $\begin{array}{l}\text { Behind } \\
\text { PTV/Orion }\end{array}$ \\
\hline$\overline{\mathrm{FBCP}}$ & 1.0 (assumed) & 0.9516 & 0.8605 \\
\hline Drogue & 1.0 (assumed) & 0.9997 & 0.9418 \\
\hline Pilot & 1.0 (assumed) & $\sim 0.78$ & TBD \\
\hline Main & 1.0 (assumed) & $\sim 1.0$ (assumed) & $\sim 1.0$ (assumed) \\
\hline
\end{tabular}

Fig. 5-22 of Ref. 6 lists the wake PRF values assumed during the Apollo program for their $16.5 \mathrm{ft} \mathrm{D}_{\mathrm{o}}$ Drogue. Interestingly, the CPAS $7.0 \mathrm{ft} \mathrm{D}_{\mathrm{o}} \mathrm{FBCP}$ is a better match to those values than the CPAS $23.0 \mathrm{ft} \mathrm{D}_{\mathrm{o}}$ Drogue. Apollo test vehicles are described in Ref. 26. The slender Apollo Instrumented Cylindrical Test Vehicle (ICTV) assumed a wake factor of 1.0, similar to the CPAS MDTV. The cone shaped "PTV" used by Apollo had a PRF of 0.92, similar to the PRF of 0.95 behind the missile shaped CPAS PCDTV. The Apollo boilerplate PRF was 0.82 while the Orion boilerplate was 0.86 . However, average CPAS Drogue PRF values are significantly higher than those for the Apollo Drogue.

\section{Conclusion}

CPAS has normalized the parachute drag area distributions according to the forebody test vehicle. This was accomplished through statistical analysis of mean performance in each of the different configurations. Scale factors are applied to the original data sources to treat them as if they were collected in the presence of the target forebody.

Further investigations of wake effects may be performed using a finite element line sail model, which should model the trajectory of the mortar-deployed canopy better than the high fidelity model used in FAST.

\section{Acknowledgments}

The author would like to acknowledge Phil Stuart of NASA-JSC for developing the wake model.

American Institute of Aeronautics and Astronautics 


\section{References}

${ }^{1}$ Morris, A. L., et al., "Simulating New Drop Test Vehicles and Test Techniques for the Orion CEV Parachute Assembly System," $21^{\text {st }}$ AIAA Aerodynamic Decelerator Systems Technology Conference and Seminar, Dublin, Ireland, May 2011, AIAA paper 20112616.

${ }^{2}$ Morris, A. L., et al., "Summary of CPAS Gen II Testing Analysis Results," $21^{\text {st }}$ AIAA Aerodynamic Decelerator Systems Technology Conference and Seminar, Dublin, Ireland, May 2011, AIAA paper 2011-2585.

${ }^{3}$ Romero, L. M., et al., "Summary of CPAS EDU Testing Analysis Results," $23^{\text {rd }}$ AIAA Aerodynamic Decelerator Systems Technology Conference, Daytona Beach, Florida, March 2015, AIAA paper 2015-2179.

${ }^{4}$ Moore, J. W. and Romero, L. M., “An Airborne Parachute Compartment Test Bed for the Orion Parachute Test Program,” $22^{\text {nd }}$ AIAA Aerodynamic Decelerator Systems Technology Conference, Daytona Beach, Florida, March 2013, AIAA paper 2013-1289.

${ }^{5}$ Moore, J. W. and Romero, L. M., "A Boilerplate Capsule Test Technique for the Orion Parachute Test Program," $22^{\text {nd }}$ AIAA Aerodynamic Decelerator Systems Technology Conference, Daytona Beach, Florida, March 2013, AIAA paper 2013-1290.

${ }^{6}$ Knacke, T. W., "Parachute Recovery Systems Design Manual", Para Publishing, Santa Barbara, California, 1992.

7 Ray, E., Bretz, D. R., and Morris, A. L., "Photogrammetric Analysis of CPAS Main Parachutes," $21^{\text {st }}$ AIAA Aerodynamic Decelerator Systems Technology Conference and Seminar, Dublin, Ireland, May 2011, AIAA paper 2011-2538.

${ }^{8}$ Ray, E. and Bretz, D. R., "Improved CPAS Photogrammetric Capabilities for Engineering Development Unit (EDU) Testing," $22^{\text {nd }}$ AIAA Aerodynamic Decelerator Systems Technology Conference, Daytona Beach, Florida, March 2013, AIAA paper 20131258.

${ }^{9}$ Stuart, Phil C., "Orion Crew Module Pressure Recovery Fractions”, EG-CAP-12-27, 22 March 2012, NASA/JSC EG3.

${ }^{10}$ Buning, P. G., Gomez, R. J., and Scallion, W. I. "CFD Approaches for Simulation of Wing-Body Stage Separation," AIAA $22^{\text {nd }}$ Applied Aerodynamics Conference, Providence, RI, Aug. 2004, AIAA Paper 2004-4838.

${ }^{11}$ Ray, E., "Reconstruction of Orion EDU Parachute Inflation Loads," $22^{\text {nd }}$ AIAA Aerodynamic Decelerator Systems Technology Conference, Daytona Beach, Florida, March 2013, AIAA paper 2013-1260.

12 NovAtel, Inc., "SPAN-SE," NovAtel, Inc. web site [online], July 2012, URL: http://www.novatel.com/assets/Documents/Papers/SPAN-SE.pdf [cited 10 October2016].

13 NovAtel, Inc., "HG1700 SPAN," NovAtel, Inc. web site [online], 2008, URL: http://www.novatel.com/assets/Documents/Papers/HG1700_SPAN62.pdf [cited 10 October 2016].

${ }^{14}$ Ray, E. and Morris, A. L., "Measurement of CPAS Main Parachute Rate of Descent," $21^{\text {st }}$ AIAA Aerodynamic Decelerator Systems Technology Conference and Seminar, Dublin, Ireland, May 2011, AIAA paper 2011-2545.

${ }^{15}$ Romero, L. and Ray, E., "Application of Statistically Derived CPAS Parachute Parameters," ," $22^{\text {nd }}$ AIAA Aerodynamic Decelerator Systems Technology Conference, Daytona Beach, Florida, March 2013, AIAA paper 2013-1266.

${ }^{16}$ Ray, E., "CPAS Engineering Development Unit Operating Modeling Parameters Version 16 (Critical Design Review Closeout)," JETS-JE11-13-SAIP-MEMO-0020, JSC Engineering Technology and Science contract, Jacobs Engineering, August 2016.

${ }^{17}$ Ray, E., Romero, L., and Bledsoe, K., “CPAS Simulation of Drop Test Vehicles and Test Techniques Version 16," JETS-JE1113-SAIP-MEMO-0021, JSC Engineering Technology and Science contract, Jacobs Engineering, August 2016.

${ }^{18}$ Ray, E., Hennings, E., and Bernatovich, M. A., "Testing Small CPAS Parachutes Using HIVAS," 22 $2^{\text {nd }}$ AIAA Aerodynamic Decelerator Systems Technology Conference, Daytona Beach, Florida, March 2013, AIAA paper 2013-1309.

${ }^{19}$ Ray, E., "A Symmetric Time-Varying Cluster Rate of Descent Model," 23rd AIAA Aerodynamic Decelerator Systems Technology Conference, Daytona Beach, Florida, March 2015, AIAA paper 2015-2137.

${ }^{20}$ Ray, E. and Machín, R. A., "Pendulum Motion in Main Parachute Clusters," 23 ${ }^{\text {rd }}$ AIAA Aerodynamic Decelerator Systems Technology Conference, Daytona Beach, Florida, March 2015, AIAA paper 2015-2138.

${ }^{21}$ Morris, A. L., Olson, L., and Taylor, T., "Load Asymmetry Observed During Orion Main Parachute Inflation," $21^{s t}$ AIAA Aerodynamic Decelerator Systems Technology Conference and Seminar, Dublin, Ireland, May 2011, AIAA paper 2011-2611.

${ }^{22}$ Ray, E., "Reefing Line Tension in CPAS Main Parachute Clusters," $22^{\text {nd }}$ AIAA Aerodynamic Decelerator Systems Technology Conference, Daytona Beach, Florida, March 2013, AIAA paper 2013-1393.

${ }^{23}$ Sengupta, A., et al., "Performance of a Subscale CPAS Conical Ribbon Drogue Parachute in a Turbulent Wake," $22^{\text {nd }}$ AIAA Aerodynamic Decelerator Systems Technology Conference, Daytona Beach, Florida, March 2013, AIAA paper 2013-1307.

${ }^{24}$ Becker, J., Johnson, S., and Yechout, T., "Investigation of NASA Orion Wake Effects on Drogue Chute Aerodynamic Characteristics," 21 $1^{\text {st }}$ AIAA Aerodynamic Decelerator Systems Technology Conference and Seminar, Dublin, Ireland, May 2011, AIAA paper 2011-2539.

${ }^{25}$ Kolesar, R. and Yechout, T., "Experimental Investigation of NASA Orion Pilot Chute Drag Characteristics," $22^{\text {nd }}$ AIAA Aerodynamic Decelerator Systems Technology Conference, Daytona Beach, Florida, March 2013, AIAA paper 2013-1355.

${ }^{26}$ Ray, E. S., and Morris, A. L., "Challenges of CPAS Flight Testing," $21^{\text {st }}$ AIAA Aerodynamics Decelerator Systems Technology Conference, Dublin, Ireland, May 2011, AIAA paper 2011-2557.

American Institute of Aeronautics and Astronautics 